
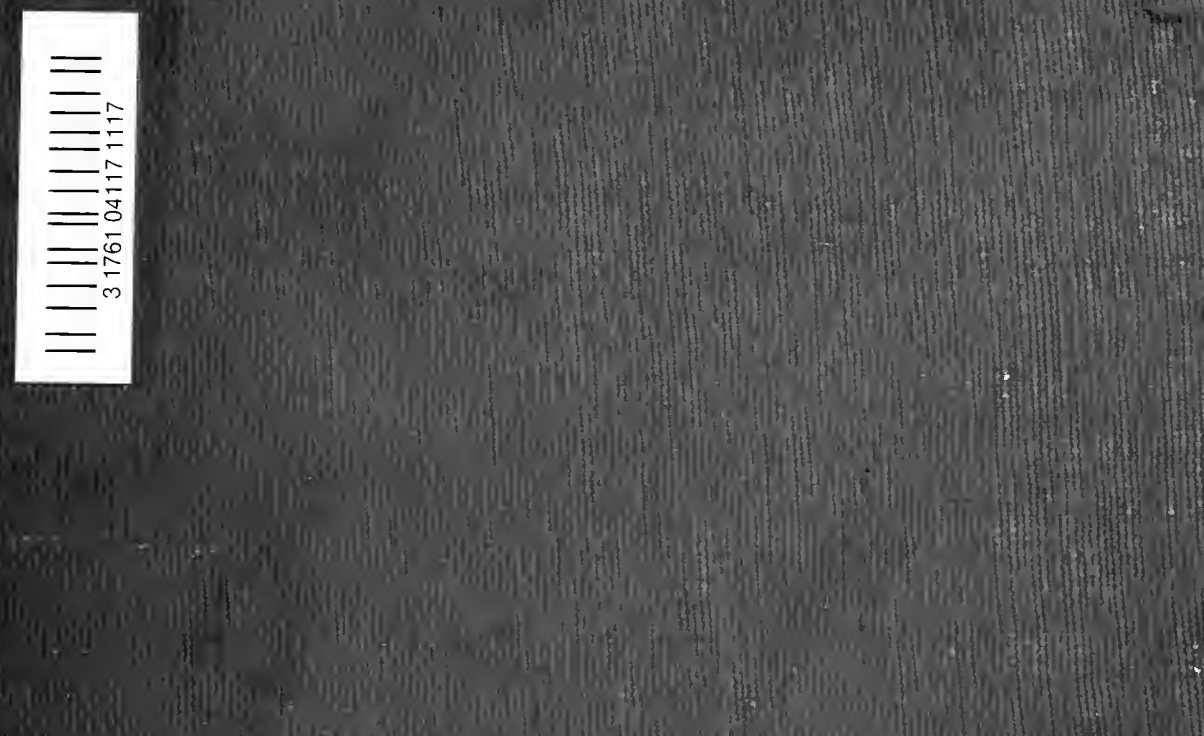

\title{
(INVV.

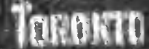






\title{
The Color Sensitivity of the PERIPHERAL RETINA
}

BY

\author{
JOHN WALLACE BAIRD
}

Of the Department of Psychology, Johns Hopkins Unizersity

Research Assistant, Carncgie Institution of Washington, 1903-1904

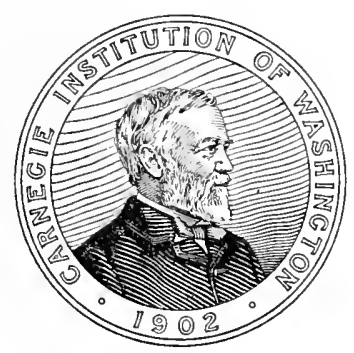

WASHINGTON, D. C. :

Published by the Carnegie Institution of Washington May, 1905 
Carnegie institution of Washington, Publication no. 29. 


\section{CONTENTS.}

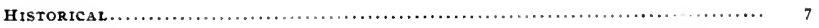

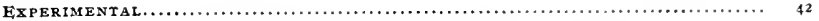

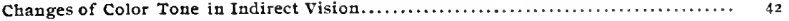

The Relative Extension of the different Color Zones upon the Retina............... 59

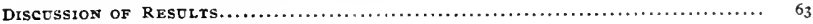

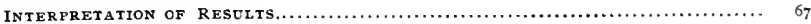

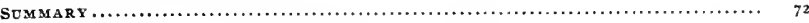

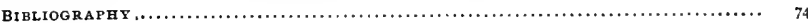




\section{Digitized by the Internet Archive in 2008 with funding from Microsoft Corporation}




\title{
THE COlOR SENSITIVITY OF THE PERIPHERAL RETINA.
}

\author{
By John WaLlace Baird,
}

This paper is the result of an experimental investigation conducted during the year I903-4 in the Psychological Laboratory of Cornell University. It aims to make a contribution to our knowledge of the phenomena of indirect vision. It will present data obtained by the writer in a series of experiments upon the peripheral retina, and will attempt to correlate these data with the phenomena previously established, and with the theoretical principles advanced from time to time by other investigators.

An unequivocal and undisputed statement of the facts of the case is, of course, a necessary prerequisite to satisfactory progress in the domain of theory. So long as uncertainty prevails as to what sensations arise under given conditions of color stimulation, there can be no definite and certainly no unanimous envisagement of the process of color vision. That the investigation of the present problem has yielded wholly different results in the hands of different investigators is only too patent from the literature; but in late years a distinct tendency has set in toward harmony in the findings of the various experimenters who have attacked the problem, and it appeared for a time that we were at last upon the verge of a unanimity of agreement. The hope that this goal was ultimately to be reached, at least along lines already laid down, was, however, dashed by the results recently published by Hellpach. It seems eminently desirable, therefore, to work over the ground covered by Hellpach with a view to verifying his data and to discovering, if possible, the ground for their variation from those of his predecessors.

It might appear that one is doomed to disappointment who attempts to solve a problem which has already been attacked without satisfactory result by so many illustrious investigators. But a perusal of the literature of the topic reveals the fact that although these investigators have for the most part failed in their ultimate object, they still made a valu- 
able contribution to the solution of the problem; and one is encouraged to grapple with it anew by a recognition of the value of this heritage from the past-a heritage which consists not only in an intimate knowledge of many of the facts of vision, but also in an extraordinary refinement of apparatus and of method. In entering into possession of this inheritance it seems distinctly worth while to go over the ground and discover its extent and value. We shall therefore preface the report of our own experiments with a detailed history of the problem; and, in the light of the accrued advantages of the present generation, we shall attempt to evaluate the results of previous investigations.

Our paper represents the work of the past year. The leisure required for a year's concentration upon this topic was rendered possible by a grant from the Carnegie Institution of Washington. The writer takes this opportunity to express his gratitude to the members of the Institution for their assistance in his undertaking.

The experiments upon which this paper is based will be described in detail in a later section.* The experimenter was in consultation throughout with Professor E. B. Titchener and Assistant Professor I. M. Bentley, to both of whom he is indebted for advice and criticism. $\mathrm{He}$ is also under obligation to Professor Lightner Witmer, of the University of Pennsylvania; to Mr. Louis Wilson, of Clark University; to Mr. Willard Austen, of the library of Cornell University; and to Major Walter D. NicCaw, of the Surgeon-General's library at Washington, D. C., for aid in obtaining access to the literature of his subject.

* See pp. $42 \mathrm{ff}$. 


\section{HISTORICAL.}

Mariotte's discovery of the blind-spot seems to have played an important part in instigating the examination of the peripheral retina. It is, however, to Thomas Young that we owe the first published account of an attempt to explore the retina with a view to determining the form and extent of its sensitive surface. Troxler attacked the problem independently a few years later and discovered that the periphery possesses a characteristic which is absent from the central regions. After the lapse of twenty years Purkinje confirmed and extended the work of Troxler in an exceedingly important series of experiments; but it was not until the days of Szokalsky and Aubert that the problem of peripheral as compared with central vision assumed definite shape, and that the characteristic features of each were investigated in detail.

In a paper read before the Royal Society of England, in I800, Thomas Young* communicated the following statement:

The visual axis being fixed in any direction, I can at the same time see a luminous object placed laterally at a considerable distance from it; but in various directions the angle is very different. Upwards it extends to 50 degrees, inwards to 60 , downwards to 70 , and outwards to 90 degrees. These internal limits of the field of view nearly correspond with the external limit formed by the different parts of the face, when the eye is directed forwards and slightly downwards, which is its most natural position. * * * The whole extent of perfect vision is little more than Io degrees; or more strictly speaking, the imperfection begins within a degree or two of the visual axis, and at the distance of 5 or 6 degrees becomes nearly stationary, until, at a still greater distance, vision is wholly extinguished. The imperfection is partly owing to the unavoidable aberration of oblique rays, but principally to the insensibility of the retina. * * * The motion of the eye has a range of about 55 degrees in every direction; so that the field of perfect vision, in succession, is by this motion extended to 110 degrees.

Troxler $f$ found that images which fall upon eccentric parts of the retina fade out rapidly and soon disappear, while those upon the central area of the retina persist. This peculiarity of indirect vision he discovered accidentally while engaged upon an attempt to prove that the blind-spot is not wholly insensitive to light, as its discoverer had stated. Troxler had pasted a series of white paper figures upon a light-blue background, and was surprised to find that when each was fixated monocularly in turn, all of the others gradtually paled out and finally

*Thomas Young. On the Mechanism of the Eye, Philosophical Transactions, XCII, I801, pp. 23ff; Miscellaneous Works of Thomas Young, London, 1855, pp. 12ff.

tD. Troxler. Ueber das Verschwinden gegebener Gegenstände innerhalb unseres Gesichtkreises. Himly und Schmidt's Ophthalmologische Bibliothek, Jena, 1804, II, 2, S. 1-53. 
disappeared, leaving nothing but the uniform background and the fixation-object. Similar experiments with papers of various colors showed that certain tones disappear more rapidly in indirect vision than do others. The degree of persistence of the retinal image is, in his opinion, conditioned by two factors-the color of its object and the angular distance of the object from the fixation-point. The latter factor he explains, in part at least, in terms of luminosity of image; the former he makes no attempt to explain, nor even to describe in satisfactory detail. It is to be noticed in this connection that the manner of disappearing, as described by Troxler, is peculiar and interesting. The colors gradually paled out and vanished, frequently reappearing- "floating into view as out of still water "-before ultimately disappearing.* In no case do they seem to have been followed by an after-image. $t$

Purkinje $\neq$ confirmed Troxler's observations as to the rapid fading of color from peripheral images and endeavored to bring them into relation with certain subjective phenomena-the disappearance and reappearance of objects which occurs when one is drowsy, and the floating phantoms which may be observed when one fixates a point in a dark room-both of which classes of phenomena he describes at length in his earlier paper. In his later paper he gives a more detailed discussion of central and peripheral vision, for which he proposes the names, now commonly employed, of direct and indirect vision.

There is, he says, but a single retinal point-the fovea-at which the brightness, the color, and the form of objects are seen with maximal clearness. This three-fold sensitivity of the retina diminishes with in-

* This reappearance of objects which had previously disappeared from view is doubtless due to eye-movements. Failure to maintain a constant fixation would result in the exposure, to the action of the stimulus, of a non-fatigued area of the retina; and there would ensue a series of appearances and disappearances correlate with the successive shiftings of regard and the subsequent fatigue of the new area stimulated. The absence of after-images upon the peripheral retina has been pointed out by several investigators; it was also characteristic of our own experiments. (See pp. 56 and 58 .)

$\dagger$ It is also to be noted that Aubert refers to 'Troxler as having been the first to discover that objects appear colorless in indirect vision (Grundzüge der Physiologischen Optik, S. 539). We can find no mention of this phenomenon in Troxler's paper. It is true that he speaks of the colored papers merging into the uniform (blue) background; but that this is a final stage of the process, Troxler himself is careful to emphasize. What Troxler is interested in demonstrating is the relatively rapid chromatic adaptation of the peripheral retina. That under certain conditions it is wholly insensitive to color, clearly escaped his notice.

$\ddagger$ Johannes Evangelista Purkinje. Beobachtungen und Versuche zur Physiologie der Sinne, I, Beiträge zur Kenntnis des Sehens in subjectiver Hinsicht, Prag, 1823, Sections V and IX, particularly S. 77; II, Neue Beiträge, u. s. w., Berlin, 1825, S. 3-25. Various spellings of the name of this author have crept into the literature. We have adopted the form given by Purkinje himself in the two papers cited. 
crease of distance from the fovea, until at the extreme periphery there is found a zone " not of objective blackness and darkness, but of insensibility and unconsciousness." Purkinje devised an apparatus for the purpose of determining the spatial extension of retinal sensitivity, and of investigating the phenomena of indirect vision in general. His apparatus consisted of a sheet of heavy cardboard cut in the form of a quadrant. The subject was seated in a dark room and the apparatus was brought into such a position that the pointed apex of the quadrant rested upon the bridge of his nose, while the side of the apparatus lay against his cheek. A lighted taper was then moved along the graduated arc of the quadrant and the point was noted at which the taper first appeared or disappeared from view. Purkinje's measurements of the absolute extension of the normal field of vision gave somewhat larger values than had been obtained by Young (see p. 7), namely, $60^{\circ}$ upwards, $60^{\circ}$ inwards, $80^{\circ}$ downwards, and $100^{\circ}$ outwards. In a series of experiments with color-stimuli, ${ }^{*}$ he discovered that colored objects appear gray when their images fall upon peripheral parts of the retina and that they pass through regular transitions of color tone as their images approach the fovea. Neue Beiträge, S. 15-16.) Thus, purple appeared successively black at $90^{\circ}$, blue at $80^{\circ}$, violet at $70^{\circ}$, and purplish at $50^{\circ}$; red appeared pale grayish-yellow at $90^{\circ}$ to $70^{\circ}$, then orange, and finally its true color; "bright blue" appeared white at $90^{\circ}$, bluish at $80^{\circ}$; "saturated blue" appeared white at $90^{\circ}$, bluish at $80^{\circ}$; violet appeared black at $90^{\circ}$, blue at $80^{\circ}$ to $70^{\circ}$, violet in different tones from $60^{\circ}$ onward; " saturated green " appeared black at $90^{\circ}$ and $80^{\circ}$, greenish at $70^{\circ}$; rose-red appeared white at $90^{\circ}$ and $80^{\circ}$, reddish at $70^{\circ}$; bright yellow and orange appeared in their own tones at $90^{\circ}$.

Purkinje confesses that he is unable to find a satisfactory explanation of these phenomena. He points out that peripheral images must, in the nature of the case, receive less light than central images, and discusses the influence of the yellow spot and of different conditions of optic refraction, upon color vision, but he regards these factors as inadequate to explain the transitions of color tone. He also discusses the significance for practical life of the indistinctness of indirect vision, and finally concludes (Neue Beiträge, S. 19) : "It is difficult to determine whether the clearer vision of the central part of the retina is due to the presence, at the fovea, of a greater light intensity, or to a peculiar structure and a closer relation to the Seelenkraft, at that point."

* Just how these experiments were arranged is not clear from Purkinje's description. It is probable, however, that he employed the same apparatus in diffuse daylight, and that colored papers served as stimuli. 
Although Purkinje admits that the problem baffles him, he makes an important contribution toward its final solution. He was the first to observe that sensitivity to light has a wider retinal extension than sensitivity to color, that the different colors have retinal zones of different extension, and that colored objects appear in different color tones at different parts of the retina. He also discovered the significance of retinal adaptation in color vision; for in the discussion of his color experiments he recommends that the eye be closed for a time after each exposure, "um seine Empfindlichkeit zu sammeln" (1. c., S. 6).

Szokalsky* also found that sensitivity to color is not uniformly distributed over the whole retina, and that colored objects appear in different tones when their images move across the retina. His apparatus consisted of a black background, containing at its center a white fixationpoint. Pigment colors were moved in from the edges of the background towards the center. His experiments showed that purplish-red appears first black, then blue, then violet, and finally assumes a tone of purple-red, only when it is near the fixation-point; violet passes through black and blue before becoming violet; bright blue and rose-red appear white at the periphery. "The other colors," he adds, "gave similar results." In consequence of these experiments, Szokalsky conceives the retina to be made up of three concentric zones; the outermost zone is assumed to be sensitive only to black and white, the intermediate zone only to blue, yellow, black, and white, while the innermost zone is capable of sensing these four, and red besides. This happy conjecture was unfortunately not elaborated in detail by its author; its chief interest lies in the fact that it foreshadows the brilliant discovery made half a century later by Bull and Hess.

Hueck $†$ attacked the problem by means of a new method. He endeavored to determine the minimal extent of retinal image which is capable of producing a sensation of color, at the different parts of the retina, $i . e$., he set out to determine the minimum cisibile of color for various degrees of eccentricity. $\mathrm{He}$, too, found that color sensitivity decreases with increase of distance from the fovea; he confirmed the existence of Purkinje's black-white zone, but does not mention having observed any transitions of color tone. His essential contribution to the

*V. Szokalsky. Essai sur les sensations des couleurs, etc., Annales d'Oculist., II, I839, and III, I840. These papers were reprinted in book form, under the same title, Paris, 1841 ; they were subsequently elaborated and published in German (Ueber die Empfindungen der Farben in physiologischer und pathologischer Hinsicht, Giessen, I842).

†. Hueck. Von den Grenzen des Sehenvermögens, Müller's Archiv. f. Anat., Phsyiol. und wiss. Med., 1840, S. 83-98. 
literature was his discovery that the color zones are not fixed, but flexible areas, and that their extension increases with increased area of stimulus-object.

By far the most fruitful investigator of this period was Aubert.* During the progress of an investigation of the "space sense," carried on by Aubert and Foerster in 1857, it had been observed that colored objects may appear colorless in indirect vision. Aubert was able to find in the literature but two references to this phenomenon-the papers of Purkinje and Hueck; and since neither discussed the matter in satisfactory detail, Aubert determined to undertake a thorough investigation of the phenomena of indirect vision. He employed an apparatus which had but recently been devised, and which has since been named the perimeter, and set himself the task of solving the following problems:

(I) To what extent does the character of the background influence the degree of eccentricity at which a color stimulus can be recognized?

(2) What is the relation between decrease of color sensitivity and decrease of area of stimulus?

(3) Does color sensitivity decrease at a uniform rate along the various retinal meridians?

(4) Through what transitions of tone does each color pass during the movement of its image from the fovea to the periphery of the retina?

(5) What is the relative extension of the retinal areas within which stimuli appear in their true colors?

(6) In what degree are the phenomena of indirect vision analogous with those of direct vision?

Aubert's method of experimentation was as follows: From papers of different colors he cut duplicate sets of squares, varying in size from I sq. $\mathrm{mm}$. to I,024 sq. mm. One set of these squares was then moutted upon white cards, the other upon black. The perimeter was set up in a room with a northern exposure and the experiments were performed in a diffuse daylight illumination. Each sheet of cardboard was inserted in the perimeter, in turn, and was gradually moved out along a retinal

*Hermann Aubert. Ueber die Grenzen der Farbenempfindung auf den seitlichen Theilen der Netzhaut, Graefe's Archiv. für Ophthalmologie, III, 2, I857, S. 38-68; Ueber das Verhalten der Nachbilder auf den peripherischen Theilen der Netzhaut., Moleschott's Untersuchungen, IV, 1858, S. 215-240; Ueber die durch den electrischen Funken erzeugten Nachbilder, Ibid., V, I859, S. 279ff.; Untersuchungen über die Sinnesthätigkeit der Netzhaut,, Poggendorff's Annalen, CXV, 1862, S. 87-116, CXVI, 180́2, S. 249-278; Ueber subjective Lichterscheinungen, Ibid., CXVII, 1862, S. 638ff.; Physiologie der Netzhaut, Breslau, 180́5, S. 89-105 and 116-124; Grundzüge der physiologischen Optik, published in Graefe u. Saemisch's Handbuch der gesammten Augenheilkunde, II, 2, 1876, S. 393-670, republished in separate form under the same title, Leipzig, 1876. 


\section{2}

meridian until its color had wholly disappeared. Eight meridians were explored by means of each stimulus. His results may be summarized as follows :

(1) The brightness of the background has a most pronounced influence upon the extension both of the color sensitivity and of the brightness sensitivity. Red upon the white ground becomes colorless at $16^{\circ}$; upon the black ground at $30^{\circ}$. Blue upon white becomes colorless at $13^{\circ}$; blue upon black at $37^{\circ}$. Beyond the limits of the color zones, all colors appear white when the ground is black, black when the ground is white.

(2) The extension of the color zone increases with increase of area of stimulus. The former increase does not keep pace with the latter, but progresses much more slowly, as appears from the following table. The area of the stimulus-object is expressed in square millimeters; the width of the color zone is given in degrees. The squares were exposed at a distance of $20 \mathrm{~cm}$. from the eye.

\begin{tabular}{|c|c|c|c|c|c|}
\hline \multirow{2}{*}{ Color stimulus. } & \multicolumn{5}{|c|}{ Area of stimulus-object. } \\
\hline & $\stackrel{\text { I }}{\text { sq. } \mathrm{mm} .}$ & sq. $\stackrel{4}{\mathrm{~mm}}$. & $\begin{array}{c}\mathrm{I6} \\
\text { sq. } \mathrm{mm} .\end{array}$ & $\begin{array}{c}64 \\
\text { sq. } \mathrm{mm} \text {. }\end{array}$ & $\begin{array}{c}25^{6} \\
\text { sq. mm. }\end{array}$ \\
\hline Red.................... & $\underset{16}{\text { Digrees. }}$ & $\underset{\mathrm{I} 8}{\text { Degrees }}$ & $\begin{array}{c}\text { Degrecs } \\
26\end{array}$ & $\begin{array}{c}\text { Degrees. } \\
38\end{array}$ & $\begin{array}{c}\text { Degrees } \\
43\end{array}$ \\
\hline 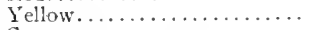 & $2 I$ & $3 I$ & 44 & $\ldots$ & .. \\
\hline Green.................... & 20 & 36 & 45 & 50 & . \\
\hline Blue................... & r 3 & 23 & 37 & 49 & 57 \\
\hline
\end{tabular}

(3) The color sensitivity decreases at very different rates upon different retinal meridians. It diminishes much more slowly, or extends much farther out, on the nasal side of the retina.

(4) The transitions of color tone are as follows: Red passes through reddish-yellow and yellowish-gray to gray; green becomes yellowish, while yellow and blue undergo no change of tone, but decrease in saturation and finally appear gray.

(5) The relative extension of the different color zones can not be determined with any degree of accuracy. Since the width of the color zone is a function of the luminosity of the stimulus, the color-stimuli employed in the determination of comparative retinal limits must all be equated in brightness. In the opinion of Aubert, the comparison of the relative brightness of stimuli of different colors is attended by such difficulties as to render its accurate accomplishment impossible. In his own experiments, with non-equated stimuli upon a black background, blue had the widest extension, red and yellow less, and green least of 
all; upon a white ground, green had the widest extension, then followed yellow, blue, and red in order. In the face of this conflicting evidence Aubert averaged the values obtained with the different backgrounds, and arrived at the following results: Blue $34^{\circ}$, yellow $33^{\circ}$, green $31^{\circ}$, and red $27^{\circ}$. From these data he concluded that there is but little difference between the extensions of the various color zones.*

(6) There is a close analogy between the functioning of the central and peripheral parts of the retina. Colored objects appear colorless in both direct and indirect vision when the visual angle is sufficiently small, when the illumination is sufficiently weak, when the stimulation is sufficiently long-continued, and when certain conditions of contrast between stimulus and background are not fulfilled. $\dagger$ Aubert argues that the only difference between the color sensitivity of different parts of the retina is a difference of degree, the "color sense" of the periphery being less acute. $\frac{\ddagger}{+}$ And this lesser sensitivity is to be explained, in part from a different distribution of retinal elements, in part, from their more rapid fatigue. $\S$

Helmloltz** pointed out that the clianges of color tone which appear in indirect vision are similar to those which occur in direct vision when the luminosity of the stimulus is progressively increased. Thus red and green become distinctly yellow, blue passes over into gray without change of tone, and purple becomes bluish. Helmholtz found that a mixture of red and green-blue which appears colorless in direct vision becomes green-blue at but a slight distance from the visual axis. From this experiment it would seem that the peripheral retina is more sensitive to blue and to green than to red. Accordingly Helmholtz assumed that the red-sensing substance is lacking at the periphery, and referred the color phenomena of indirect vision to the red-blindness of the eccentric region.

The view of Helmholtz was confirmed by Schelske, $\uparrow_{\dagger} \dagger$ who was the first to employ spectral colors in the investigation of the problem. He determined the inner limits of the red-blind zone in his own eye to be $68^{\circ}$ on the nasal side, $37^{\circ}$ on the lower side, $53^{\circ}$ in the temporal, and $38^{\circ}$ in the upper direction.

*Graefe's Archiv., 1. c., S. 55 .

†Graefe's Archiv., III, 2, S. 61.

$\ddagger$ Graefe's Archiv., III, 2, S. 61; Grundzïge, S. 545.

a Aubert devoted a paper to the phenomena of fatigue and after-images; this will be referred to in connection with our own results.

**Hermann von Helmholtz. Handbuch der physiologischen Optik., Leipzig, 1860 , S. 300-301, and S. 845. The publication of this volume covered a period extending from 1856 to 1866 . The second Licforung, which contains his first discussion of indirect vision, appeared in 1860 .

t+R. Schelske. Ueber Farbenblindheit des normalen Auges, Graefe's Archiv., IX, 3,1863 , S. $39-62$. 
A comparison of the sensations aroused by the same stimulus on the central and the color-blind areas gave the following results:

\begin{tabular}{|c|c|}
\hline Color tone seen in direct vision. & $\begin{array}{l}\text { Sensation aroused upon } \\
\text { the "red-blind" zone. }\end{array}$ \\
\hline 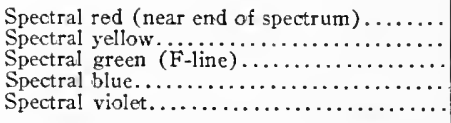 & $\begin{array}{l}\text { Dark gray. } \\
\text { Pale green.* } \\
\text { Light bluish gray. } \\
\text { Light greenish blue.* } \\
\text { Dark blue. }\end{array}$ \\
\hline
\end{tabular}

*It will be seen that in two cases his stimull appeared more greenish at the periphery than at the fovea. This result has not been confirmed by other observers; indeed there seems to be no doubt that the opposite relation obtains.

Experiments with mixed colors (pigments) gave the following:

\begin{tabular}{|c|c|}
\hline In direct vision. & In indirect vision. \\
\hline 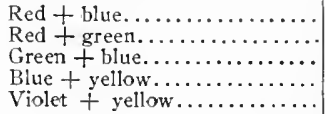 & $\begin{array}{l}\text { Appeared light bluish. } \\
\text { Appeared light grayish yellow. } \\
\text { Appeared dight bluish. } \\
\text { Appeared bluish green. } \\
\text { Appeared marine blue. }\end{array}$ \\
\hline
\end{tabular}

Schelske's investigation convinced him of the validity of the Helmholtzian theory of color vision, and of the existence of a zone of redblindness at the periphery of the retina. In common with Helmholtz he assumed that every color stimulus in direct vision excites all three sorts of color-sensing substance; in indirect vision only green-sensing and violet-sensing substances are excited. This difference in the cooperation of the visual substances in the two cases would, in the opinion of Schelske, lead one to expect just such differences in color sensitivity as are observed.

The Helmholtzian principle was accepted and extended by Woinow.* Employing pigment colors, this investigator observed the following transitions of tone when the stimulus passed out into indirect vision: Red becomes yellowish at but a slight distance from the fovea, gradually passes over into yellowish-brown, which becomes darker and darker, and finally black; if the background is much darker than the stimulus, the latter appears light gray instead of black at the periphery. Orange becomes yellowish, gradually grows murkier, and finally appears gray, light or dark according as the background is dark or light. Yellow simply decreased in saturation until it appeared light gray at the periphery. Green passes out through yellow or yellowish to gray; this stimulus never appears black at the periphery. Blue passes over

*M. Woinow. Zur Farbenempfindung. Graefe's Archiv., XVI, I, i870, S. 212-224. 
into gray with progressive decrease of saturation. Violet went out through blue to black or gray. Purple-red appears successively violetish, blue, and black or gray.

Woinow is convinced that the areas of the color zones are fixed and invariable; he finds that their limits change neither with change of area of stimulus nor with change of brightness of background. $\mathrm{He}$ does not state what is the area of each zone, nor does he give data from which their relations may be calculated. Woinow concludes that the distribution of all three visual substances becomes more and more scant towards the periphery, until only green-sensing substance is present in the outermost zone. The extreme periphery is therefore not only redblind but violet-blind as well.

Bow* discusses the problem without any reference to the previous literature, and evidently under the impression that he is the pioneer investigator in the field. He reports that a blue-green glass held before the eye and regarded indirectly appears blue, while a yellow-green glass appears yellow under similar conditions. Scarlet becomes orange at $30^{\circ}$ from the visual axis and yellow at $40^{\circ}$. Green passes over into yellow, and purple into blue, in indirect vision. On the basis of the different refrangibility of light of different colors, he advances the following remarkable explanation of his results: The retina contains a three-ply layer of sensitive elements. Each stratum is composed of fibers which are sensitive to but a single color, and each is separated from its fellows by intervening strata of non-sensitive tissue. The presence of the intermediate strata is a sine qua non of normal color vision. They are, however, absent from the peripheral retina, and since the sensitive layers are here in contact, they are incapable of functioning normally. $\dagger$

Maxwell $\neq$ found that when a white surface is observed through a bluish-green filter, the fixation-point appears to be a pinkish spot upon a bluish-green ground. He also reported that a certain mixture of red,

${ }^{*}$ R. H. Bow. On the Changes of Apparent Color by Obliquity of Vision. Proceedings of the Royal Society of Edinburgh, VII, I871, pp. 155-160.

tSince we shall not have occasion to refer to this theory again, we may remark, in passing, that the following objections have been urged against it: In order that lights of different refrangibility may be brought tQ a focus exactly upon the layers which are to sense them, the red-sensing layer must oocupy an innermost and the violet-sensing layer an outermost position; Bow gives them the reverse order. Moreover, the difference in focal distance, between the red and violet rays, in the reduced eye, is given by Helmholtz (Physiol. Optik, S. 131) as $.434 \mathrm{~mm}$. Now, the retina in its thickest part is scarcely half thick enough to meet Bow's requirement. Again, the central region is at once the thinnest part of the retina, and the most capable of diverse visual functioning.

$\ddagger \mathrm{J}$. Clerk Maxwell. On Color Vision at Different Points of the Retina. Report of the British Association for the Advancement of Science, I87o. Notices and Abstracts, etc., pp. 4 of. 


\section{I6 COLOR SENSITIVITY OF THE PERIPHERAL RETINA.}

green, and blue light which appears red in direct vision, is seen as green "when we direct the eye away from it and cast a sidelong glance at it." "The cause of this is the yellow spot, which acts somewhat as a piece of yellow glass would do, absorbing certain kinds of light more than others."

Landolt* experimented with a modified form of the Foerster perimeter, employing colored papers as stimuli. As the accompanying table shows, he obtained a much wider area of color sensitivity than any of his predecessors had done.

\begin{tabular}{|c|c|c|c|c|c|c|c|c|}
\hline $\begin{array}{c}\text { Retinal } \\
\text { meridian. }\end{array}$ & White. & Blue. & Yellow. & Orange. & Red. & $\begin{array}{c}\text { Yellow. } \\
\text { green. }\end{array}$ & $\begin{array}{c}\text { Blue- } \\
\text { green. }\end{array}$ & Violet. \\
\cline { 1 - 7 } & Degrees. & Degrees. & Degrees. & Degrees. & Degrees. & Degrees. & Degrees. & Degrees. \\
Down.... & 73 & $6 \mathrm{I}$ & 58 & 57 & 52 & 43 & 38 & 33 \\
Up....... & 78 & 67 & 62 & 60 & 59 & 50 & 44 & 33 \\
Out....... & 75 & 70 & 68 & 61 & 54 & 45 & 33 & 35 \\
In....... & 85 & 79 & 77 & 70 & 65 & 60 & 52 & 46 \\
\hline
\end{tabular}

Here, as in all other tables of this papet, the limits of the color-zones are referred to the meridians (or, more correctly, to the half-meridians) of the retina. Thus the "out meridian" of the table here appended iudicates the temporal half of the horizontal meridian of the retina, $i$. e., the retinal meridian which runs outward or temporalward from the fovea. In view of the inversion of the spatial relations which occurs when objects are imaged upon the retina, it will he seen that if the retinal positions he designated by the names of those positions in the visual field which correspond to them, the opposite relations will hold and opposite names must be employed. What we have here called the "out" meridiau (of the retina) would then he called the "in "meridian (of the visual field)-its position in the field of vision would lie inward or nasalward from the visual axis.

In these experiments, blue and yellow were perceived almost to the extreme limits of the field of vision; then follow in order, orange, red, yellow-green, blue-green, and violet. But Landolt remarks that with a sufficiently bright stimulus all colors are recognized at the periphery.

The following color changes, which Landolt observed with different degrees of eccentricity of stimnlns, are similar to those which had been reported by preceding investigators: Blue-green and violet pass throngh bluish to gray; yellow-green and orange pass through yellow; red through yellowish-red or brown and yellowish, while blue and yellow undergo no change save decrease of saturation.

Landolt finds an analogy between the phenomena of indirect vision and those of direct vision with faint illumination. No part of the normal retina is wholly insensitive to color of any tone ; the term color-blind

*E. Landolt. Il perimetro e la sua applicazione, Annali d'Ottalmologia, 1871, pp. 465-484; Farbenperception der Netzhautperipherie, Zehender's Klinische Monatsblätter für Augenheilkunde, XI, 1873. S. 376-577. De la perception des couleurs à la périphérie de la rétine, Annales d' Oculistique, LXXI, I874, pp. 44-45. Papers by Landolt are also to be found in the Sitzungsbericht der Ophthalmologischen Gesellschaft, 1873, and in Graefe und Saemisch's Handbuch der Gesammten Augenheilkunde, III, 1873. 
is inappropriate and can not properly be applied even to the extreme periphery. There is no evidence of a difference in structure between the various parts of the normal retina. The keener sensitivity of the fovea and paracentral region can be explained in terms of greater luminosity of retinal image. This, of course, is a definite rejection of the explanation offered by Helmholtz. An important feature of Landolt's papers is his insistence that no investigation of color vision is complete unless it takes into account the condition of retinal adaptation and determines the relative luminosity of the stimuli employed.

Briesewitz* employed circular discs of colored paper, which he moved in from the periphery upon a black background. His exploration of four normal retinas yielded the following results: There is a gradual decrease of color sensitivity with increasing distance from the fovea; this decrease is most rapid on the temporal retina; yellowish-red and green appear yellow, and reddish-blue appears bluish at the periphery. Yellow and blue are perceived farther out on the retina than red, and red farther than green.

Raehlmann's $\nmid$ investigation was carried through, both with pigment and with spectral colors. His results show that red passes over through orange into yellow; violet becomes blue, and green passes out through yellow, while blue and yellow do not change in tone in indirect vision. He found that yellow and blue have the widest retinal zones, but his data as to the relative extensions of the other color zones is of a most conflicting character. The color limits were found to vary with changing brightness of stimulus and with changing conditions of refraction.

In his earlier paper Raehlmann was inclined to accept the Helmholtzian principle of explanation, but in his later discussions he rejects this position and explains the phenomena in terms of a lesser degree of illumination at the periphery.

Raehlmann's third paper attempts to determine and express quantitatively the relative sensitivity of different parts of the retina to light of different colors. Behind a slit in the ocular of a spectroscope he pivoted a Nicol prism; the part of the spectrum which served as the stimulus passed through the slit and fell upon this prism, where its

\footnotetext{
*Briesewitz. Ueber das Farbensehen bei normalen und atropischen $\mathrm{N}$. Opticus. Inaug. Diss., Griefswald, 1872.

$\dagger$ E. Raehlmann. Ueber Farbenblindheit in den peripherisohen Netzhautpartien, u. s. w., Inaug. Diss., Halle, 1872; Ueber Verhältnisse der Ferbenempfindung bei indirecten und directen Sehen, Graefe's Archiv., XX, 1, 1874, S. 15-32; Ueber Sohwellenwerte der verschiedenen Spectralfarben an verschiedenen Stellen der Netzhaut., Graefe's Archiv., XX, I, S. 232-254; Daltonismus und die Youngsche Farbentheorie, Graefe's Archiv., XXII, 1, S. 20-64; Ueber relativen und absoluten Mangel des Farbensinnes, Berlin, 1900.
} 
intensity was regulated at will by rotating the latter. From that setting of the prism at which the color of the stimulus was just recognized, it was possible to calculate the minimal luminosity of stimulus required to produce the sensation of color. * The following table, which has been compiled from Raehlmann's results (Schwellenwerte, u. s. w., S. 249), shows the rate at which the retinal sensitivity to the various colors decreases in indirect vision:

\begin{tabular}{|c|c|c|c|c|c|}
\hline Relative sensitivity. & Red. & Yellow. & Green. & Blue. & violet. \\
\hline At the center............ & 4.18 & 1.29 & 6.47 & 3.74 & I.OI \\
\hline At $30^{\circ}$ from the center.... & 3.17 & I. 10 & 1.94 & I.6I & .85 \\
\hline At $60^{\circ}$ from the center.... & I & I & I & I & I \\
\hline
\end{tabular}

Lamansky† also correlates the phenomena of indirect vision with Purkinje's phenomenon. His investigation, already referred to, convinces him that the retina is less sensitive to red than to any other color. Hence it is but natural that the sensitivity to red should be the first to be lost in indirect vision, in twilight vision, and in pathological conditions of the retina.

Krükowł was a pupil of Woinow, and in general confirmed the results of his master. For stimuli he employed three sizes of squares of red, green, and blue paper; these he moved out from the visual axis, before a light and a dark background. He found that red and green pass over into yellow before becoming colorless, while blue undergoes no change of tone. The color zone of blue is widest and that of red is narrowest. These zones are fixed and invariable; their limits are influenced neither by the area of the stimulus nor by the brightness of the background. Krïkow accepts the Helmholtzian explanation of his results ( $i$. $c$., the partial color-blindness of the peripheral retina), but admits that the possibility of sensing yellow at parts of the retina where sensitivity to red and to green is lacking, is difficult for the Helmholtzian hypothesis to explain.

*Unfortunately this method does not take into account the widely different brightnesses (and saturations) of the different parts of the spectrum. The results obtained in experiments with different color tones are therefore not expressed in terms of a common standard of brightness (or saturation). They are, for that reason, valueless as a means of comparing the retinal sensitivity to the various color tones. The same objection may be urged against the work of Lamansky, Dobrowolsky, Mandelstamm, and Cattell.

$\dagger$. Lamansky. Ueber die Grenzen der Empfindlichkeit des Auges für Spectralfarben, Graefe's Archiv., XVII, 1, I871, S. 123-134. The same paper also appears in Poggendorff's Annalen, CCXIX, is7i, S. ó $33-6+3$.

$\ddagger$ Krükow. Sur la sensation des couleurs à la périphérie de la rétine, Dissertation, Moscow, I873; Objective Farbenempfindung auf den peripherischen Theilen der Netzhaut., Graefe's Archiv. XX, I. 1874, S. 255-296. 
Schirmer* also employed squares of colored paper, which he brought in from the periphery, against a black background. His blue and yellow papers did not change in tone; the red, orange, and green stimuli first appeared yellow, and the violet and purple came in as blue. Green had the smallest zone, then red, orange, purple, violet, yellow, and blue, which latter had the widest zone of all. The zones had no fixed limits, but varied with variations of brightness and area of stimulus.

Schirmer's study of the abnormalities of color-vision yielded an interesting result. He found that in progressive atrophy of the optic nerve, the color zones gradually decrease in area, until in the final stages of the disease the pathological macula has become functionally equivalent to the normal periphery. The disease progresses so slowly and so regularly that a great variety of successive stages may be differentiated between its earliest inception and its final stage of total color-blindness. Sensitivity to green is the first to go, then that to red, to yellow, and finally that to blue.

Schön † also discusses color vision in its normal and pathological aspects. Employing pigment colors, he found green to have the smallest color zone and blue the largest, red occupying an intermediate position. Schön explains the phenomena of indirect vision from a different retinal sensitivity to the different colors. As a result of this difference of sensitivity, the minimal brightness at which the various colors can be perceived is different. Green requires the greatest luminosity, red less, and blue least of all. Atrophy of the optic nerve does not affect any particular sort of color-sensing fiber alone, but reduces the sensitivity of all three sorts of fibers in equal degree. The color sensitivity of the retina diminishes toward the periphery, in the same degree as the luminosity of peripheral images decreases. In both cases sensitivity to green is the first to go, and sensitivity to blue is the last. Both classes of phenomena are to be explained in terms of decreased brightness.

Chodin $\ddagger$ attacked the problem by a new method. He attempted to determine the magnitude of the minimal sector of colored paper which

${ }^{*} \mathrm{R}$. Schirmer. Ueber erworbene und angeborene Anomalien der Farbenempfindung, Berliner Klinische Wochenschrift, 1873, No. 5; Ueber erworbene und angeborene Anomalien des Farbensinns, Graefe's Archiv., XIX, 2, 1873. S. 19-4-235.

$\dagger$. Schön. Ueber die Grenzen der Farbenempfindung in pathologischen Fällen, Zehender's Klinische Monatsblätter für praktische Augenheilkunde, JuliAugust, 1873, S. I71-227; Die Lehre vom Gesichtsfelde und seine Anomalien, Berlin, 1874; Einfluss der Ermüdung auf die Farbenempfindung, Graefe's Archiv., $\mathrm{XX}, 2,1874$, S. $273-284$.

$\mp$ A. Chodin. Zur Lehre von den Farbenempfindungen auf der Peripherie der Netzhaut, Petersburger Medicinischer Anzeiger, 1875, Nos, 10-13; Ueber die Abhängigkeit der Farbenempfindungen von der Lichtstärke, Sammlung Physiologischer Abhandlungen von W. Preyer, I, 7, I877, S. I-66; Ueber die Empfindlichkeit für Farben in der Peripherie der Netzhaut, Graefe's Archiv., XXIII, 3, 1877, S. 177-208. 
must be introduced into a rotating disc, in order that the color in question may be perceived. His determination of liminal color stimulus was made, not only for the fovea, but for various points upon the peripheral retina, as well. He hoped by this means to obtain a quantitative expression of the relative sensitivity of various parts of the retina to light of different color tones. Chodin remarks in his introduction: "It is self-evident that in comparing the retinal sensitivity to different colors, the color-stimuli employed must be of equal brightness and of equal saturation."* But this very essential condition was not fulfilled in his own experiments. His results are therefore invalid, in so far as they refer to the relative sensitivity to different tones.

They do show, however, that color sensitivity is invariably much less at the periphery than at the fovea, the amount of decrease ranging from 93 per cent (blue) to about 99.75 per cent (green). Chodin confesses that he is unable to find a satisfactory explanation of this difference between direct and indirect vision.

Klugt employed a gas spectrum and worked in a dark room. He found blue to have the widest zone, then came green and yellow, then red and orange, and finally violet. The color limits are extended by brightening the stimulus and by increasing its area. Beyond the zones of specific color sensitivity violet appears blue, orange appears yellow, yellow appears green, while red, green, and blue undergo no change of tone. Klug's explanation of these phenomena is similar to that of Helmholtz.

Charpentier determined for various parts of the retina the minimal visual angle at which a stimulus appears in its own color. He concludes that all parts of the retina are most sensitive to blue, less to red, and least to green. Color sensitivity is greatest at the center and decreases somewhat uniformly towards the periphery. With moderate stimulation he found that the zone of blue has the widest extension and that of green the narrowest; but with appropriate increase of stimulus, all colors may be recognized at the extreme periphery. All parts of the retina are equally sensitive to white light; and all respond to chromatic stimulation with an initial sensation of pure brightness. This achromatic sensation persists only during the first instant of stimulation if the color-stimulus possess more than a certain degree of brightness, but

*Graefe's Archiv., XXIII, 3. S. I78.

†F. Klug. Ueber Farbenempfindung bei indirectem Sehen, Graefe's Archiv, XXI, 1, 1875, S. 25I-294.

A. Charpentier. De la vision avec les diverses parties de la rétine, Archives de Physiologie, IV, 1877, pp. 894-895. Reprinted under same title, Paris, 1877. La lumière et les couleurs, Paris, I888. Landolt et Charpentier. Des sensations de lumière et de couleur, dans la vision directe et dans la vision indirecte, Comptes Rendus, LXXXVI, 1878, pp. 495-497. 
lasts throughout if the stimulus be of very slight intensity. Both Landolt and Charpentier hold that color vision is the joint product of a two-fold physiological process. One of these processes has its seat in the retina and is relatively simple and primitive in character. The other is cerebral and is of a more higlily developed nature. The cerebral process comes about more readily in proportion to the number of times its nervous apparatus has been called upon to function. The lesser sensitivity of the periphery is to be explained in terms of less frequent functioning, $i$. e., of relatively defective training.

Treitel* employed squares of white and colored paper, which he moved in towards the fixation-point upon a perimeter. He found that white has the widest retinal zone; then follow blue, red, and finally green. From the results of a second experiment, which consisted in exposing red, green, and blue squares of different sizes at various parts of the visual field, Treitel concluded that the peripheral retina is least sensitive to green and most sensitive to blue; and that sensitivity to all colors decreases towards the periphery. He fails to find a satisfactory explanation of these phenomena, but is inclined to refer them to the retina rather than to the optic nerve proper, or to the brain.

Donders's $\dagger$ method consisted in obtaining color equations for peripheral regions of the retina. He found that the peripheral retina (about $40^{\circ}$ from the fovea on the temporal side) functions very much like the foveal region of the green-blind eye. Red, orange, yellow, and green here appear alike; nor can blue, indigo, and violet be distinguished from one another. With certain degrees of saturation and brightness of stimulus, however, the specific color tone of each appears, but only lasts for an instant.

Donders is of the opinion that no part of the periphery is colorblind. It was he, by the way, who first suggested to Landolt that all colors can be perceived upon the outermost regions of the retina if only the stimulation be sufficiently intensive. But he believes that the color sensitivity of the periphery is so weak as to approximate in some degree the condition of the dichromatic, or even of the monochromatic retina. The periphery possesses a "color sense" which is simply less highly developed than that of the fovea.

*Th. Treitel. Prïfung des Gesichtsfelds mit Pigmentfarben, Inaug. Diss, Königsberg, 1875; Ueber das Verhalten der peripheren und centralen Farbenperception bei Atrophia nervi optici, Königsberg, 1875; Ueber den Werth der Gesichtsfeldsmessung mit Pignenten für die Auffassung der Krankheiten des nervösen Sehapparats, Graefe's Archiv., XXV, 2, 1879, S. 29-130. 3, S. I-1 10; Ueber das Verhalten der normalen Adaptation, Graefe's Archiv., XXXIII, 2, i887, S. 73-112; Ueber den Lichtsinn der Netzlautperipherie, Graefe's Archiv., XXXV, 1, 1889, S. 50-75.

$\dagger \vec{F}$. C. Donders. Uober Farbensysteme, Graefe's Archiv., XXVII, I, I88t, S. 155-223; Noch einmal die Farbensysteme, Graefe's Archiv., XXX, I, 1884, S. $15-90$. 
Bull* made an important contribution to the literature of the topic. In discussing the relative extension of the color zones he had the insight to recognize that the final solution of this much-disputed problem can never be reached unless two conditions are fulfilled by the investigator: He must employ stimuli whose saturations and brightnesses have been equalized; and he must choose for stimuli such colors as do not change in tone in peripheral vision. Both of these conditions he claims to meet in his own investigation. His "physiologically pure" colors are a purplish red, a bluish green, a yellow, and a blue. $\dagger \mathrm{He}$ found that the limits of the purple-red zone coincide with those of the blue-green zone, while those of the yellow and the blue approximately coincide; the latter pair of zones is considerably wider than the former pair. Here are his results:

\begin{tabular}{|c|c|c|c|c|}
\hline \multirow{2}{*}{ Retinal meridian. } & \multicolumn{4}{|c|}{$\begin{array}{c}\text { Extreme distance at which the color of } \\
\text { the stimulus was recognized. }\end{array}$} \\
\hline & Red. & Green. & Blue. & Yellow. \\
\hline Down $. . . \ldots \ldots \ldots, \ldots \ldots$ & $\underset{17}{\text { Degrees. }}$ & $\begin{array}{c}\text { Degrees. } \\
\text { is }\end{array}$ & $\begin{array}{c}\text { Degrees. } \\
28\end{array}$ & $\underset{22}{\text { Degrees. }}$ \\
\hline Down-in .................... & $2 \mathrm{I}$ & 23 & 3I & 27 \\
\hline In $\ldots \ldots \ldots \ldots \ldots \ldots \ldots$ & 38 & 39 & 50 & $4 \mathrm{I}$ \\
\hline 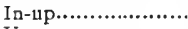 & $3 \mathrm{I}$ & 29 & 45 & 47 \\
\hline 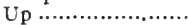 & 23 & 21 & 30 & 28 \\
\hline Up-out ........................ & 17 & 17 & 30 & 28 \\
\hline 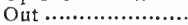 & 20 & 20 & 29 & 30 \\
\hline Out-down .............. & 21 & 20 & $3 I$ & 30 \\
\hline
\end{tabular}

*Ole Bull. Studien über Licht- und Farbensinn, Graefe's Archiv., XXVII, I, 1881, S. 54-154; Bemerkungen über den Farbersinn unter verschiedenen physiologischen und pathologischen Verhältnissen, Graefe's Archiv., XXIX, 3, 1883, S. 7I-II6; Sur la périmètrie au moyen de pigments colorés, Annales d' Oculist., CX, 1893, pp. I69-I81; same title, Ann. d'Ocul., CXI, I894, pp. 284-285; Perimetrie, $1 v+2 \mathrm{I} 8$, Bonn., 1895 .

TThe equating of the four stimuli was accomplished by two methods. Since his stimuli constituted two pairs of complementary colors, the mixture of each pair in certain proportions gave gray. Now, when gray resulted from the mixture of equal proportions of the purplish red and the bluish green, or of yellow and blue, $i$. $\varepsilon$, when $180^{\circ}$ of the one just neutralized $180^{\circ}$ of its complementary, the components were taken to be equivalent in saturation. The comparison of relative brightness was facilitated by the interpolation of intermediate color tones; thus while it is difficult to make a subjective estimate of the relative brightness of a green and a blue stmulus, the matter is simplified when we have to deal with a green and an adjacent bluish green. When these two have been equated, the latter may readily be equated with a green which contains still more blue, etc. This method of paired comparison would finally give us a variety of color tones, all of equal brightness. For the sake of control, the four stimuli were subjected to a final test. All four were mounted upon a uniform gray ground and regarded under such conditions-with partially closed eyelids-that they appeared colorless. Any error which might have crept into the previous comparison of brightnesses was revealed by this control.

$\ddagger$ Graefe's Archiv., XXVII, I, plates at end of article; Ann. d'Ocul., CX, p. I77. 
Bull is convinced that the color sensitivity of the periphery differs in many respects* from that of the center of the retina, and that the periphery does not function in a manner which is comparable with the center in twilight illumination. He believes that Hering's theory furnishes a fairly satisfactory explanation of the phenomena of indirect vision, but that it fails to account for all of the facts.

Von Kriest made a comparative study of the phenomena of indirect vision and the phenomena which occur with decreasing area of stimulus. He found that in moving out towards the edge of the field of vision yellow and blue stimuli appear to pass over into gray without change of tone, while all other colors tend to appear more and more yellowish or bluish as they approach the periphery. That the changes of color which result from decrease of visual angle are a wholly different series is evident from the following table:

With increasing eccentricity of vision.

Red passes over through yellow to gray

Orange passes over through yellow to gray.

Greenish-yellow passes over through yellow to gray.

Yellowish-green passes over through yellow to gray.

Bluish-green passes over through blue to gray.

Blue passes over directly to gray.

Violet passes over through blue to gray.
With decreasing visual angle.

Red passes over directly to gray.

Orange passes over directly to gray.

Greenish-yellow passes over directly to gray.

Yellowish-green passes over directly to gray.

Bluish-green passes through greenish and yellowish-green to gray.

Blue passes over directly to gray.

Violet passes over through reddish to gray.

Later papers by von Kries contain additional data and a theoretical discussion of the whole topic. A comparison of the relative brightnesses of the different parts of the spectrum as they appear to the normal periphery, to the twilight-adapted retina, and to the periphery of the red-blind, convinces von Kries of a dissimilarity of function in these various cases; while the distribution of brightness is approxi-

*Graefe's Archiv., XXVII, I, S. I52f.

$\dagger \mathrm{J}$. von Kries. Gesichtsempfindungen und ihre Analyse, Du Bois-Reymond's Archiv für Anatomie und Physiologie, Physiol. Abtheilung, Supplement-Band, 1882; republished in separate form under same title, Leipzig, I882, S. 89-106; Ueber die functionellen Verschiedenheiten des Netzhautcentrums und der Nachbartheile, Graefe's Archiv., XLII, 3, 1896, S. 95-133; Ueber die Farbenblindheit der Netzhautperipherie, Zeitschrift f. Psy. u. Phys. d. Sinnesorgane, XV, 1896, S. 247-279.

$\ddagger$ Gesichtsempfindungen, u. s. w., S. 93 . 
mately identical for the normal and the green-blind retinas. These data are claimed by von Kries to furnish a confirmation for his general theory of vision. But his attempt to account for the color-phenomena of indirect vision is far from being successful. He discusses the hypotheses advanced by Helmholtz and by Fick [This latter conception will be discussed later. See pp. 39f.] to explain these phenomena, but refuses to accept either. He is inclined to posit an integrity of structure and of function in the normal periphery, and to refer the lesser sensitivity of that region to a more central part of the visual mechanism, i. e., to conditions which exist in the cortex or possibly in the optic nerve proper. This conjecture is only tentative, however, for in the opinion of von Kries the time is not yet ripe for a final decision of the matter.*

Wolffberg + employed colored papers as stimuli, and worked with a wide range of luminosities. He found the blue zone to be greatest, the red zone to be less, and that of green to be least. The limits of the color zones contract very slowly with decreasing luminosity of stimuli; thus when the luminosity had been reduced from $\frac{15}{15}$ to $\frac{3}{1 \cdot 5}$, the zonal limits decreased by only $15^{\circ}$. When the luminosity was still farther reduced, the zones successively contracted to the vanishing-point-red being the first to disappear, then green, and finally blue.

Dobrowolskyt attempted to determine the relative sensitivity of various parts of the retina to light of different colors. His stimulus was a narrow band of the solar spectrum, and his method consisted in determining the minimal shifting of the spectral band in the ocular of his apparatus, which rendered possible the judgment that a different

*Zeitschrift, XV, S. 27off. Von Kries has published yet another paper upon this topic since the present monograph was written. (Nagel's Handbuch der Physiologie des Menschen, Braunschweig. I904. III, I ; Die Gesichtsempfindungen, Johannes von Kries, S. 109-282, especially S. 193-204 and 266-282.) His most recent contribution is for the nost part a résumé of the results of his previous papers. After reviewing the phenomena of indirect color vision, which he persists in referring to the color-blindness of the peripheral retina, he repeats his discussion of the distribution of spectral brightnesses. It seems evident throughout that the belavior of the eccentric regions of the retina has given von Kries an endless amount of trouble; and his own discussion shows that his theory is wholly inadequate to account for the phenomena in question. In his final pronouncement upon the topic he is more favorable in his attitude toward Fick's hypothesis than the facts of the case would seem to warrant; but he ultimately grants the validity of the Hering theory, in so far at least as the color phenomena of indirect vision are concerned. (Handbuch, S. 273-274.)

tL. Wolffberg. Ueber die Priffung des Lichtsinns, Graefe's Archiv., XXXI, I, 1885. S. 1-78.

$\neq$ W. Dobrowolsky. Ueber die Empfindlichkeit des normalen Auges gegen Farbentöne anf der Peripherie der Netzhaut, Graefe's Archiv., XXXII, I, I886, S. $9-32$. 
color tone had appeared. From the magnitude of the shifting required in any given case, he was able to calculate the relative sensitivity of a given retinal region to the color of the stimulus employed.

In the following table the foveal sensitivity to each stimulus is taken as a standard; the sensitivity of points along the nasal meridian is expressed in terms of the standards. *

\begin{tabular}{|c|c|c|c|c|c|}
\hline & $\begin{array}{c}\text { Red } \\
\text { (C-line). }\end{array}$ & $\begin{array}{l}\text { Yellow } \\
\text { (D-line). }\end{array}$ & $\begin{array}{c}\text { Green } \\
\text { (E-line). }\end{array}$ & $\begin{array}{c}\text { Blue } \\
\text { (F-line). }\end{array}$ & $\begin{array}{c}\text { Blue } \\
\text { (G-line). }\end{array}$ \\
\hline Fovea $\ldots \ldots \ldots \ldots \ldots \ldots \ldots$ & $\mathbf{I}$ & I & I & I & I \\
\hline & I & I & I & I & $\mathbf{I}$ \\
\hline 5 degrees......... & I.4 & 2 & I.39 & 2.08 & I.7 \\
\hline & I & $\mathbf{I}$ & I & I & I \\
\hline 20 degrees............. & 2.6 & 2.4 & I.6I & 2.68 & 1.9 \\
\hline & I & I & I & I & I \\
\hline 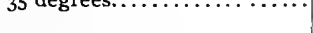 & 3 & 2.75 & $2.4 \mathrm{~S}$ & 287 & 2.4 \\
\hline & I & I & I & I & I \\
\hline 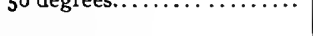 & 4 & 2.88 & 3 & 3 & 3 \\
\hline & & I & I & I & $\mathbf{I}$ \\
\hline 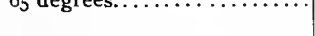 & & 3.76 & $5 \cdot 34$ & 3.25 & 4.2 \\
\hline & & -1 & $\underline{\mathbf{I}}$ & I & I \\
\hline so degrees. ...... & & 4.8 & 8 & 3.49 & $4 \cdot 7$ \\
\hline & & I & -.- & I & $\mathbf{I}$ \\
\hline 90 degree & & 5.6 & . & 3.6 & 6 \\
\hline
\end{tabular}

This table shows that color sensitivity is keenest at the fovea; that it decreases gradually toward the periphery, and that the rate of decrease is different for different colors and for different parts of the retina. Dobrowolsky also found that practice tends to extend the limits of the color zones. During a period of thirteen years, which had for the most part been devoted to spectroscopic experiments, his sensitivity to all colors had increased by about one-half. It is interesting to note, however, that this improvement was confined to the eye that had been used in his experiments; his left (unused) eye showed no increase of sensitivity during this period.

Albinit had discovered that the "form sense" of the peripheral retina is improved when the peripheral error of refraction is corrected

* Dobrowolsky, 1. c., S. 23.

†E. Albini. Della visione indiretta delle forme e dei colori, Giornale della R. Aocademia di Med. di Torino, XXXIV, 1886, p.p. 657-675; Sulla visione indiretta delle forme e dei colori, Annali di Ottalmologia, XV, I887, pp. 482-485. 
by means of appropriate lenses. An examination of the color sensitivity of indirect vision by a similar method resulted in the discovery of a similar state of affairs as regards the "color sense." Albini's method consisted in determining the extreme angular distance at which the colors of a series of stimuli could just be recognized, and in subsequently redetermining the color limits of the same stimuli when lenses of different refractive powers were interposed. The lens was in every case held obliquely before the eye, its position being such that the visual axis did not pass through it; the plane of the lens was at right angles to the path of the central ray of colored light coming to the eye from the stimulus-object. This arrangement permitted the fixation-point to be seen by the naked eye, while the stimulus light passed perpendicularly through the lens before it reached the eye.

The following excerpts from Albini's tables show the general character of his results:

\begin{tabular}{|c|c|c|c|}
\hline & Blue. & Red. & Green. \\
\hline 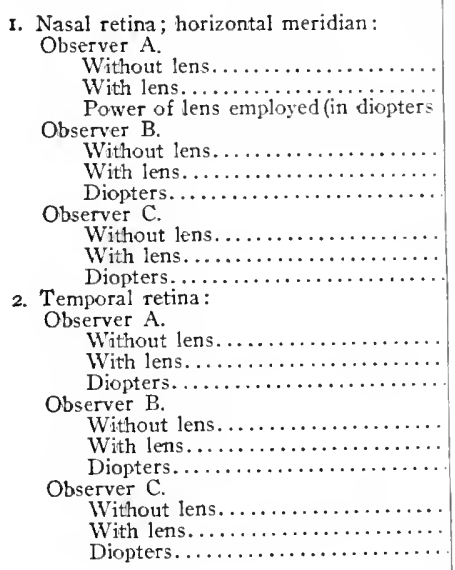 & $\begin{array}{r}48^{\circ} \\
81^{\circ} \\
+9.5 \\
65^{\circ} \\
90^{\circ} \\
+8.5 \\
55^{\circ} \\
90^{\circ} \\
+7.5 \\
\\
39^{\circ} \\
57^{\circ}-60^{\circ} \\
+6.5 \\
45^{\circ} \\
60^{\circ} \\
+7 \\
43^{\circ} \\
55^{\circ} \\
+6.5\end{array}$ & $\begin{array}{r}48^{\circ} \\
\mathrm{S}^{\circ} \\
+\mathrm{10.5} \\
58^{\circ} \\
90^{\circ} \\
+10 \\
55^{\circ} \\
90^{\circ} \\
+10 \\
\\
35^{\circ} \\
59^{\circ} \\
+10 \\
43^{\circ} \\
57^{\circ} \\
+9 \\
41^{\circ} \\
55^{\circ} \\
+8\end{array}$ & $\begin{array}{r}45^{\circ} \\
80^{\circ} \\
+12 \\
50^{\circ} \\
90^{\circ} \\
+12 \\
50^{\circ} \\
57^{\circ} \\
+13 \\
\\
33^{\circ} \\
57^{\circ} \\
+12.5 \\
43^{\circ} \\
57^{\circ} \\
+10 \\
41^{\circ} \\
55^{\circ} \\
+9.5\end{array}$ \\
\hline
\end{tabular}

Albini finds that the extension of the color zone is invariably increased by the use of a convex lens, and that the increase of a given color zone is directly proportional to the refractive power of the lens 
employed. But a given lens extends the limits of different color zones by unequal amounts; it has the greatest influence in the case of blue, less for red, and least for green. He points out that this order is the same as the order of the relative extension of the three zones upon the retina of the naked eye, and expresses his results in the general statement that the amount of refractive correction which is required to equalize the extension of the three zones is inversely proportional to their normal extension.

Albini reports that he has established the existence of a progressive error of refraction for light which falls more and more obliquely upon the eye, and concludes that the lesser color-sensitivity of the peripheral retina is due chiefly to this error of refraction. He also mentions the inferior training of the extra-foveal regions as a subsidiary principle of explanation. He is convinced that his results do not support the view that sensations of color and of brightness are furnished by different sets of retinal apparatus.

The work of Hess* is in many respects a continuation and a refinement of Bull's investigation. Hess employed colored papers and worked with light-adaptation. He found that all colors between yellow and red, and between yellow and green, gradually lose their red or green tints and appear successively yellowish, yellow, and gray, when their images fall upon more and more peripheral parts of the retina; while under similar circumstances all colors lying between blue and green and between blue and red (in the closed spectrum) gradually become blue and finally gray. From these observations it was but natural to expect that certain tones of red, yellow, green, and blue could be found which undergo no change of tone in indirect vision. Hess succeeded in building up these "unveränderliche" $\dagger$ tones, and it was with these stimuli that the remaining part of his investigation was chiefly concerned. The chromatic absorption of the macula modifies the appearance of colors seen in direct vision. For this reason, Hess confined his experiments to the exploration of the paracentral and peripheral parts of the retina.

Before proceeding to his more detailed investigation, Hess redetermined the stable colors, by means of spectral light. He found the stable green to be $495 \mu \mu$, yellow $574.5 \mu \mu$, and blue $47 \mathrm{I} \mu \mu$. None of the spectral reds proved to be a stable tone; but from an appropriate

*Carl Hess. Ueber den Farbensinn bei indirectem Sehen, Graefe's Archiv., XXXV, 4 , I889, S. I-62.

tWe shall refer to these as "stable" colors, a term which here signifies those color-stimuli which experience no change of tone in passing across the retina. 
mixture of red and violet the desired tone was obtained. This latter tone was found to be complementary to the stable green; and the stable yellow turned out to be complementary to the stable blue.

In his more accurate investigation of the behavior of the stable colors in indirect vision, Hess employed the Hering color-mixer.* In this apparatus the color-stimulus is observed through an aperture in a gray screen. By moving the fixation-point in a lateral direction, the image of the stimulus is made to fall upon the peripheral retina. The brightness of the background may be brought to equality with that of the stimulus by an appropriate inclination of the screen. By this means it is possible to secure accurate judgments as to the exact point of appearance or disappearance of the color, since in indirect vision the stimulus may be made to fuse into the gray background.

With stable stimuli whose white-values and color-values had previously been equalized, Hess proceeded to determine the limits of retinal sensitivity.

The following shows the extension of the four color-zones: $\dagger$

\begin{tabular}{|c|c|c|c|c|}
\hline Retinal meridians. & Red. & Green. & Yellew. & Blue. \\
\hline 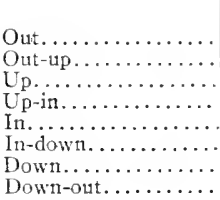 & $\begin{array}{l}\text { Degrees. } \\
21.2 \\
16.7 \\
17 \\
28.4 \\
43.6 \\
33 \\
14.2 \\
16\end{array}$ & $\begin{array}{l}\text { Degrees. } \\
21.6 \\
16.4 \\
16.9 \\
29.2 \\
42.6 \\
31.6 \\
14.2 \\
15.6\end{array}$ & $\begin{array}{c}\text { Degrees. } \\
35.6 \\
33.4 \\
31.9 \\
\ldots \\
\ldots \\
\ldots \\
\ldots \\
\ldots\end{array}$ & $\begin{array}{c}\text { Degrees. } \\
35 \\
32.8 \\
32.2 \\
\cdots \\
\cdots \\
\cdots \\
\cdots \\
\cdots\end{array}$ \\
\hline
\end{tabular}

A survey of these results reveals two interesting facts-a coincidence on the one hand of the retinal linits of sensitivity to red and to green, and on the other of those to yellow and to blue; a considerably wider extension of the yellow-blue zone than of the red-green zone. Hess also found that an increased saturation of stimulus gives an increased extension of zonal limits; he further demonstrated that the zonal limits are widened by an increase in the area of the color stimulus.

*This apparatus is figured in Titchener's Experimental Psychology, Vol. I, Part 2, igol, p. 20.

†Hess, l. c. S. 45 ff. Cf. also his tables, S. 49 f. Hess expresses his results in $\mathrm{cm}$; for the sake of uniformity we have reduced his readings to degrees. ( $1 \mathrm{~cm} .=$ about $2^{\circ}$, S. $4_{4} 6$ ) 
Hess's paper does not contain a theoretical discussion of his data, but Hering follows with a paper in which he shows that the theories advocated by Helmholtz and by Fick can not be reconciled with the results of Hess's investigation.**

Basevit employed a Masson disc, upon which were exposed his color stimuli in different degrees of brightness and saturation. He found blue to have the widest retinal zone, and green the narrowest, the relative extensions being, green 1, red I.14, yellow 1.19, and blut 1.32.

Basevi's adaptation experiments yielded the following results: The extension of the color zones is increased by dark-adaptation, but all are not increased in equal degree. The greatest increase occurs in the case of the yellow, then follow green, red, and blue in order. It follows from this that the peripheral sensitivity to all colors is increased by dark-adaptation. Basevi also performed a series of experiments to determine the influence of chromatic adaptation. After the retina had been exposed to each color for a time, each of his stimuli was presented in minimal brightness. The brightness was gradually increased until the color was recognized, the liminal brightness required for recognition being recorded in each case. The following results were obtained: With red-adaptation, green was the first color to be recognized, then came blue, then yellow, and finally red; with blue-adaptation the order was yellow, red, green, and blue; with green-adaptation. red, blue, yellow, and green; with yellow-adaptation red was the first to be recognized, then blue, green, and yellow. Unfortunately, Basevi made no determination of the color tones, or of the relative absorptions of the colored glasses employed in this experiment.

Hegg $\ddagger$ employed the Hering color-nixer to determine the four stable colors and to equate their white-values and their color-values. Then, in order that his subsequent perimeter experiments might be carried on more conveniently, he had a painter prepare exact duplicates of the four stimuli thus determined and equated. The parts of the perimeter which were to serve as background in the investigation were

*E. Hering. Ueber die Hypothesen zur Erklärung der peripheren Farbenblindheit, Graefe's Archiv., XXXV, 4, I889, S. 63-83.

†V. Basevi. Sulla sensibilità della periferia della retina per la luce e per $\mathrm{i}$ colori, Annali di Ottalmologia, XVIII, 1889, pp. +1-52: Influenza dell' adattamento strlla sensibilità retinica per la luce e per i colori, Ibid., XVIII. 1890, pp. $475-48$ I.

†Emil Hegg. Zur Farbenperimetrie, Graefe's Archiv., XXXVIII, 3, 1892, S. 145-168; La périmètrie des couleurs, Annales d'Oculistique, CIX, 3. $1893, \mathrm{pp}$. 321-347; Sur la périmètrie au moyen de pigments colorés, Annales d’Oculistique, CXI, 1894, pp. 122-127. 
painted in a gray color of the same brightness as the stimuli. His perimetric exploration of the retina gave the following results :*

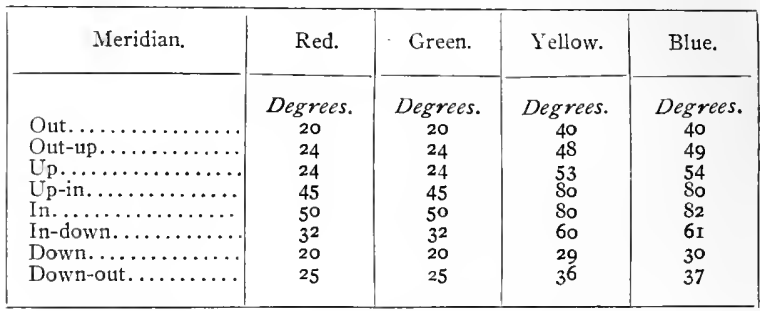

It will be seen from this table that Hegg found, in agreement with Bull and with Hess, that the limits of the red and the green zones coincide, as also do those of yellow and blue; and that the zone of the latter pair is wider than that of the red and green. Similar experiments performed with a smaller area of stimulus gave a lesser extension of the zones of all four colors (l. c., p. 343).

Kirschmann $\dagger$ found in experiments with non-equated spectral stimuli that blue has the widest zone, and violet the narrowest ; the order of the intermediate zones as found by this investigator is (in descending order), yellow, orange, red, and green. Increase of luminosity of stimulus seems to have no influence upon the width of the zones, and increase of area of stimulus is followed by increased extension of color zone in some cases only. In a second series of experiments, Kirschmann employed colored papers representing a great variety of color tones, saturations, and brightnesses. The zones determined by means of these stimuli extend farthest out on the nasal and upper portions of the retina; their limits do not run parallel with each other, but intersect and re-intersect in a most irregular fashion. It is quite impossible to tell from his determinations what is the relative extension of the different zones, since their relative widths differ upon different meridians. It would appear, however, that blue has the greatest extension and violet the least. The red and the green stimuli employed by Kirschmann did

* Ann. d'Ocul., CIX, p. 343. For the sake of uniformity, and in order to facilitate a comparison with the results of other investigators, we have referred Hegg's readings to retinal meridians; in his paper they are referred to the corresponding meridians of the visual field. It will be noticed that Hegg found the yellow-zone to be slightly narrower than the blue-zone. This state of affairs Hegg believes to be due to the greater refrangibility of blue light.

tA. Kirschmann. Die Farbenempfindung in indirectem Sehen, Philosophische Studien, VII, 1893, S. 592-6I4. 
not give co-extensive zones, nor did his blue and yellow stimuli. Kirschmann sees in these results an argument against the theories of Helmholtz and of Hering, but he fails to find an explanation for the phenomena which he reports.*

Abney† performed a great many experiments in which spectral colors were exposed in different brightnesses and at different visual angles. Employing as stimuli, red $(670.5 \mu \mu)$, yellow $(589.2 \mu \mu)$, green $(508.5 \mu \mu)$, and blue $(460.3 \mu \mu)$, whose relative brightnesses were $.3: 4.5: 2.1: .4$, he found blue to have the widest zone, yellow and red lesser zones, and green the least of all. With complementary pairs of stimuli, of widely different brightness-saturation not stated-he found the green $(500 \mu \mu)$ and blue $(460 \mu \mu)$ zones to be approximately coincident, that of red $(650 \mu \mu)$ to be narrowest, and that of yellow-green $(56 \mathrm{I} \mu \mu)$ to be widest of all. In yet another experiment he employed red, yellow, green, and blue light in nine different intensities-each stimulus being half as bright as its predecessor. He found that decrease of brightness invariably decreases the extension of the color zone, and moreover each halving of the brightness contracts the zone by an approximately equal (absolute) amount. So, too, an equal increase of area of stimulus invariably increases the extension of the zone by an approximately equal amount, until the stimulus subtends a visual angle of $5^{\circ}$ or more. He sees no reason why the limits of all color zones could not be made to coincide by an appropriate choice of luminosity and area of stimulus.

Drott $\ddagger$ worked in daylight illumination with red, green, and blue papers. His stimuli were presented in the form of squares which ranged in size from $2 \mathrm{sq}$. $\mathrm{mm}$. to $4 \mathrm{sq}$. $\mathrm{cm}$. No determination was made of the color tones employed, nor of their relative brightnesses and saturations. His results indicate that with well-saturated stimuli, blue is perceived at greatest distance from the fovea and red at least distance, while with

*It is to be noted that Kirschmann's stimuli were equated neither in whitevalue, nor in color-value. The results of his determinations of the different color-zones are for that reason wholly incomparable with each other. Nor did Kirschmann make any attempt to employ stable color stimuli. Even in his "experimentum crucis" (S. 598), where he proposes to test the validity of Hering's interpretation of the results of Hess, Kirschmann fails to fulfill any one of the three conditions demanded by the experiment. It was, of course, inevitable that such a procedure should yield wholly negative results.

$+W$. de W. Abney. The Sensitiveness of the Eye to Light and Color, Nature, XLVII, I893, pp. 538-512; The Sensitiveness of the Retina to Light and Color, Phil. Trans., I90A, I897, pp. I53-193; The Color Sensations in Terms of Luminosity, Phil. Trans., 193, I900, pp. 259-289.

†Anton Drott. Die Aussengrenzen des Gesichtsfeldes für weisse und farbige Objecte beim normalen Ange, Inaug. Diss., Breslau, I894, S. I-32. 
poorly saturated stimuli the relative distances of the red and the green are reversed. The limits of the zones vary with changes in area of stimulus.

Luckey* made a comparative study of the retinal extension of color sensitivity in individuals who differed in age, sex, and training in color discrimination. His apparatus consisted of a series of non-equated colored papers, a perimeter, and a campimeter. He found the relative extension of the zones to be (in descending order), blue, yellow, orange, red, green, and violet. The zones extended farthest out on the upper nasal region of the retina. Yellow and blue did not clange in tone in indirect vision; all other colors appeared yellow (thus, green, red, and orange stimuli) or blue (violet stimulus) before assuming their own tones. Children have narrower zones than adults; there is no variation correlate with difference of sex, and little or no increase of zonal extension as a result of previous training in color discrimination.

Hellpach $\uparrow$ explored the dark-adapted retina with stimuli of approximately spectral purity. He devised a new form of perimeter, which consisted essentially of an arrangement by means of which a moveable stimulus-lantern could be exposed at any part of the visual field. He employed red, orange, yellow, green, blue, violet, and purple stimuli, which he built up by inserting appropriate combinations of colored gelatines in the forward part of his lantern. These stimuli were equated neither in white-value nor in color-value. His results are characterized by two novel features; his yellow stimulus arouses the sensation of yellow upon no part of the peripheral retina, and all of his stimuli tend to appear in their complementary tones at the extreme periphery. Hellpach is convinced of the existence of four concentric zones upon the retina: (I) a central zone upon which all stimuli appear in their true colors; (2) a paracentral zone where certain stimuli appear in adjacent or transitional zones, $c$. g., violet appears blue upon this region; (3) a more peripheral zone where all stimuli appear colorless, and (4) an outermost zone where they appear in tones which are complementary to their true colors, $\epsilon$. g., violet here appears yellowish. His stimuli gave non-coincident zones of red and green, and of blue and yellow. Hellpach believes that his investigation overthrows the Young-Helmholtz and the Hering theories, but he feels it is yet too early to attempt to replace them by a more satisfactory conception.

${ }^{*}$ G. W. A. Luckey. Comparative Observations on the Indirect Color Range of Children, Adults and Adults Trained in Color, American Journal of Psychology, VI, 4, I895, pp. 489-504.

tW. Hellpach. Die Farben.wahrnehmung im indirecten Sehen, Phil. Studien, $\mathrm{XV}, 1900$, S. $524-554$. 
Guillery* attacked the problem by an unusual method. He built up the four stable colors upon a color-mixer, and introduced into his observation-tube an adjustable diaphragm which enabled him to vary the area of his stimulus at will. His aim was to determine the liminal extent of colored surface which constitutes an adequate stimulus for different regions of the retina, $i . e$., to determine for different parts of the retina the minimal area of retinal image in which each of the four colors can be recognized. His stimuli were not of uniform white-value and color-value.

The accompanying table shows the relative areas of the "liminal images," which Guillery calculated from the settings of his diaphragm.

\begin{tabular}{|c|c|c|c|c|c|c|c|c|}
\hline \multirow{2}{*}{$\begin{array}{l}\text { Distance } \\
\text { from the } \\
\text { fovea. }\end{array}$} & \multicolumn{4}{|c|}{ Blue. } & \multicolumn{4}{|c|}{ Yellow. } \\
\hline & In. & Out. & Up. & Down. & In. & Out. & Up. & Down. \\
\hline o degrees.... & .019 & & & …..... & .007 & & & ........... \\
\hline 10 degrees... & .035 & .037 & .045 & .04 & .03 & .033 & .025 & .032 \\
\hline 20 degrees... & $\therefore \ldots . . .$. & .063 & .072 & .08 & ............. & .068 & .068 & .079 \\
\hline 25 degrees... & .503 & & & & .067 & 126 & 15 & "........ \\
\hline 30 degrees... & $\ldots \ldots . .$. & .13 & .15 & .15 & .......... & $\begin{array}{l}.120 \\
\ldots . . .1 . . .\end{array}$ & $\begin{array}{l}.15 \\
.35\end{array}$ & .14 \\
\hline $\begin{array}{l}35 \text { degrees... } \\
40 \text { degrees... }\end{array}$ & $\begin{array}{l}.004 \\
\ldots \ldots \ldots\end{array}$ & .17 & .32 & .32 & ............. & .16 & & .31 \\
\hline 50 degrees... & .229 & .28 & ......... & ................. & $.2 \mathrm{I}$ & .29 & & ............ \\
\hline 60 degrees... & $\cdot 387$ & & & n........... & .45 & & & $\cdots \cdots$ \\
\hline \multirow{2}{*}{$\begin{array}{l}\text { Distance } \\
\text { from the } \\
\text { fovea. }\end{array}$} & \multicolumn{4}{|c|}{ Red. } & \multicolumn{4}{|c|}{ Green. } \\
\hline & In. & Out. & Up. & Down. & In. & Out. & Up. & Down. \\
\hline o degrees... & .007 & & & & $.0 I I$ & & & \\
\hline Io degrees... & .059 & .06 & .08 & .08 & .07 & .08 & .09 & .08 \\
\hline \multirow{2}{*}{20 degrees.. } & & .13 & $.1 S$ & .2 & \multirow{3}{*}{$\begin{array}{c}.17 \\
.1 .\end{array}$} & .17 & .17 & .17 \\
\hline & .14 & & & & & & & \\
\hline 30 degrees... & ........ & $.2 S$ & $\cdot 34$ & .4 & & .28 & $\cdot 3^{2}$ & $\cdot 32$ \\
\hline \multirow{3}{*}{$\begin{array}{l}35 \text { degrees... } \\
40 \text { degrees.. } \\
50 \text { degrees.. } \\
60 \text { degrees.. }\end{array}$} & .29 & .63 & 77 & .6 & \multirow{3}{*}{$\begin{array}{c}.33 \\
\ldots . .1 . \\
.64 \\
\ldots . . . .\end{array}$} & .6 & .6 & .59 \\
\hline & .6 & & $\cdot \pi$ & .0 & & & & .59 \\
\hline & & & ..... & ......... & & & ..... & .............. \\
\hline
\end{tabular}

A survey of these results shows that at every retinal region investigated by Guillery, the sensitivity to red is approximately equal to the sensitivity to green; while every retinal region also possesses an approximately equal sensitivity to yellow and to blue. In short, Guillery, by a wholly different method, has, to some extent at least, confirmed the results of Bull, Hess, and Hegg. The author himself remarks that if

*- Guillery. Vergleichende Untersuchungen über Raum-, Licht- und Farbensinn in Zentrum und Peripherie der Netzhaut, Zeitschrift für Psychologie und Physiologie der Sinnesorgane, XII, 1896, S. 243-313. 
the white-values and the color-values of his stimuli had been equated, the coincidence of his values would doubtless have been even more complete. Guillery explains his results in terms of the Hering theory.

Tschermak* made an elaborate investigation in $1897-8$, in which he employed both spectral and pigment colors. His experiments establish the fact that the disappearance of color in indirect vision is conditioned by numerous factors. His results may be summarized in the statement that the capacity to perceive color in indirect vision is a function of the extent of retinal surface stimulated, of the color-tone, the saturation and the brightness condition of adaptation of the visual organ.

NotE.-Our manuscript was in the hands of the publishers when Peters's recent paper appeared. (W. Peters. Die Farbenempfindung der Netzhautperipherie bei Dunkeladaptation und konstanter subjectiver Helligkeit, Archiv für die Gesamte Psychologie, III, 4, 1904, S. 354-387.) Our estimate of his method and results will be found in the Journal of Philosophy, Psychology, and Seientific Methods, II, I, I905, pp. 20 ff.

To summarize the results of this voluminous literature, and to present, in small compass, the conclusions which have been reached, is not an easy task. It is, however, a task which must be undertaken if one is to understand and appreciate the present status of the problem. We shall attempt, then, to find at least some general tendencies running through the literature, and to indicate, if only in a general way, the goal toward which they seem to tend.

One might be tempted, at first sight, to believe that there is an utter absence of agreement in the findings of the various investigators, and to feel that opinion is no less sharply divided as to what are the facts of indirect vision, than as to how these facts are to be interpreted and explained. But even in the midst of an undeniable confusion as to particular details, one may readily see that there are certain facts of observation upon which all investigators are agreed. And even the most discordant data will, in many cases, cease to baffle and confound us, if we but examine them in the light of the different conditions of

*A. Tschermak. Beobachtungen über die relativen Farbenblindheit in indireotem Sehen, Pflüger's Archiv für die Gesamte Physiologie, LXXXIII, I900, S. $559-591$.

$\dagger$ Under brightness is included both absolute and relative luminosity of stimulus, $i$. $e$., its own brightness and its brightness-contrast with its background. 
method and apparatus under which they were obtained, and evaluate them in the light of the widely different degrees of scientific insight and of appreciation of the difficulties of the problem, which their sponsors display.

All investigators agree that the central and paracentral regions of the retina possess the keenest sensitivity to color; and all are agreed that this acuteness diminishes in a more or less gradual and regulat manner towards the periphery. Moreover, the more recent workers at least, are of the opinion that even the peripheral retina is not, strictly speaking, color-blind. Its " color sense" may be so weak that a relatively strong stimulation is required to call forth the whole manifold of sensation qualities which it is capable of furnishing; but that it may, under appropriate conditions, furnish the same qualitative series as the more acute central regions, is no longer doubted.

The difference of opinion as regards the mode of interpretation which best fits these and other data is, after all, just what was to be expected under the circumstances. For, so long as color theorists fail to agree in their envisagement of the physiological process which conditions the seeing of color, it is neither unnatural nor perhaps undesirable that different interpretations should be put upon the findings of the various investigators.

Any attempt to obtain a definite characterization of the decrease of color sensitivity which is characteristic of indirect vision, or to define the belavior of the peripheral retina in the presence of color stimuli, reveals the existence of two distinct problems: What changes of color occur, and where do they occur? Or, more specifically, (I) what are the transitions of tone through which a color stimulus appears to pass, during the movement of its image across the retina? And, (2) what is the relative extension of the retinal zones within which the various color stimuli appear in the different transitional tones?

(I) The first of these problems is obriously much more easy of solution than the second. The factors which determine what changes of tone shall take place in a given case, are evidently much less complex than are those which determine the relative distance from the fovea at which the changes shall appear. And since, moreover, the investigator is concerned, in the former case, with the determination of absolute values only, while in the latter case he has to do with relative values, it becomes evident that the second problem is complicated by a multiplicity of co-operating factors. So long as the stimuli employed by the investigator of absolute change of tone, possess a fair degree of saturation and of brightness, so long as they subtend visual angles of moderate 
magnitude, his results will turn out to be regular and uniform, provided, of course, he is careful to maintain a uniform degree of retinal adaptation throughout his experimentation. There is here no necessity for an accurate equalization of stimuli. Hence the factors which he is required to take into account and to control, are at once few in number, relatively simple in character, and easily handled. And it is doubtless to this fact of lesser liability to error of method that the general agreement in the results of the various investigators of the first problem is due. These results may be summarized in the following general statement: All colors tend to assume a yellowish or a bluish tint as they approach the periphery; yellow and blue do not themselves change in tone, but the less refrangible end of the spectrum-the reds, the oranges, and the greens-together with the more reddish purples, appear more and more yellowish as they recede from the visual axis; while the more refrangible end of the spectrum-the violets-together with the violetish purples, pass over into bluish or even blue, at but a slight distance from the fovea. To this bald statement of the facts of indirect vision, every investigator-with the exception of Schelske, Klug, and Hellpach-could subscribe with a clear conscience. The following propositions have also been maintained: The saturations of all color stimuli appear to diminish gradually and steadily, from the forea to the outer limits of vision; in addition to the yellow and the blue, a certain tone of red and a certain tone of green undergo no change of color in indirect vision. The first of these propositions is in accord with the observations of the majority of investigators; some, however, make no mention of the phenomenon of decreasing saturation. The second proposition is a product of only the most recent literature; it has, however, been confirmed in several instances, and has never been called in question by any investigator whose work bears evidence of a knowledge of the precautions to be observed in accurate experimentation.

(2) A similar degree of unanimity is, unfortunately, not to be found in the results of the investigations which have sought to determine where, in passing out over the retina, the changes of color appear. Nor is the reason far to seek. The degree of eccentricity at which the transition of tone will occur, in any given case, is a product, not of one, but of several contributing factors. Numerous investigators have established the fact that this degree of eccentricity varies with variations in the color tone, in the saturation, in the brightness, and in the area of the stimulus employed, and with changes of optic refraction and of retinal adaptation as well. Since the investigator of this problem must 
therefore take into account the influence of all of these co-operating factors, since, too, it turns out that they are non-independent variables, and that they are, for that reason, difficult to control, he finds himself called upon to exercise the highest degree of foresight and caution. Several investigators have, indeed, attempted to solve the difficulty by cutting the Gordian knot. Failing to appreciate the magnitude of their task, they have ignored the existence of certain of these essential conditions; and they have employed methods which invited disaster from the outset, simply because no provision was made for the control of the determinants of the values which it was hoped to establish. Needless to state, these experiments have been barren of result, so far as the solution of the present problem is concerned. The influence of unequal brightness seems to have been the chief obstacle in the path of this type of investigator. It has been established in hosts of instances that change of luminosity of stimnlus is, within limits, invariably attended by a corresponding change in the extension of the retinal zone within which the color of the stimulus is recognized. Not only has this fact been reestablished at frequent intervals during the past fifty years, but its validity has never been disputed by any investigator whose stimuli covered an adequate range of luminosities. Its significance for the problem is self-evident. No determination of the relative extensions of the various color zones can ever yield really comparative results unless it be accomplished by means of stimuli of equal brightness, or, more correctly, of equal white-value. Nothing could be clearer. Yet only a very few investigators have appreciated the significance of this fact.

The conditions with which one has to deal here are analogous with those which exist in the domain of audition. An illustration borrowed from acoustics may therefore serve to emphasize our point. It is a familiar fact that the range of audibility of tones is a function of their intensity. Now, let us suppose that we wish to discover whether the carrying power of tonal stimuli is not also a function of their pitch. And let us suppose further that for the stimuli to be employed in our investigation. we choose at random a series of tones whose intensities we neither know nor care to determine. Is it not clear that our results would be valueless, and that they would warrant no inference whatever as to the relation which we set out to investigate?

Yet an equally haphazard procedure has been followed in many of the attempts which have been made to determine the relative range of visibility of a series of color tones. That the pioneers in this field should, in their generation, have failed to appreciate the significance of one or other of the factors under discussion, is not surprising. But 
that an error should recur at frequent intervals in face of repeated demonstrations of its erroneousness, and that it should reappear in such recent investigations as those of Kirschmann and of Hellpach, is scarcely comprehensible. Yet an examination of the work of these two writers shows that their experiments and discussions proceed throughout upon the tacit assumption that the retinal extension of color sensitivity is a function solely of the color tone of the stimulus; and that differences in the brightness and saturation of the stimuli employed can have no influence upon the degree of eccentricity at which the colors of the stimuli are recognized.

This fundamental objection may be urged against all of the earlier and nearly all of the later investigations of our second problem. In no investigation with spectral colors, and in only four investigations with pigment colors, have the objective conditions of experimentation been so arranged as to provide for the variation of but a single factor at a time. However valuable, then, these other experiments may be in determining the number and variety of color changes which occur in indirect vision, they are utterly incompetent to warrant any inference whatever as to the relative areas of the different color zones. And indeed of the four papers-by Bull, Hess, Hegg, and Guillery-which remain when the culling process has been completed, that of Guillery is found to have met the conditions imposed only approximately.

A survey of the papers which remain shows that all three agree in finding the following result: The retinal sensitivity to a certain red is co-extensive with that to a certain green; the sensitivity to a certain yellow is co-extensive with that to a certain blue; the former pair of color zones is much narrower than the latter pair.

Several fundamentally different conceptions have been advanced to explain the facts of indirect vision. In most instances these conceptions have been wrought out in an attempt to reconcile the facts with color theories already in the field. Since all of the present theories of color vision are the product of a comparatively recent period, and since, moreover, some of them have been modified in greater or less degree since their initial formulation, it was inevitable that in the history of our problem different interpretations should be put upon the phenomena in question.

Aubert found that the phenomena of indirect vision are analogous throughout with those of direct vision. He also discovered that the peripheral retina is much more readily fatigued than the central region, 
and that the peripheral image receives less light than does the central image. It was but natural, then, that he should attempt to correlate the observed changes of color sensation, with the observed changes in physical and physiological conditions, and to explain the former wholly in terms of the latter.* But it has since been established that Aubert's analogy between the two series of phenomena is far from being complete. Nor is his second principle of explanation adequate to account for all of the facts which his first principle leaves unexplained. It is true that the adaptation phenomena of the peripheral retina have never been submitted to a thoroughgoing investigation; but unless it be granted that this domain has genuine surprises in store for the investigator, it must be admitted that Aubert's explanation is unsatisfactory.

Maxwell conceived that the chromatic absorption of the yellow spot is sufficient to account for all of the phenomena which he observed. But inasmuch as color changes of unmistakable character occur beyond the limits of the macula, Maxwell's view must also be held to be inadequate.

Helmholtz believed that he was justified in concluding that the peripheral region of the normal retina is analogous in structure and function with the retina of the red-blind. He conceives both to be devoid of red-sensing substance, and finds in this defect an explanation of the phenomena which occur in the two cases. This conception was extended by certain of his disciples, who assumed that the violetsensing fibers also are lacking in the normal periphery. This view is untenable alike in its original and in its modified formulation. For if, as Helmholtz teaches, the sensation of white is the product of the simultaneous functioning of all three sorts of color-sensing substance, and if two, or even one, of these be absent from the periphery, then the periphery is obviously incapable of furnishing the sensation of white. Moreover, if the periphery is supplied with but a single sort of visual substance, every sort of stimulus, chromatic and achromatic, mechanical and electrical, must there arouse the sensation of blue (or green, p. 55).

The later advocates of the Young-Helmholtz theory have not failed to see the force of this objection; and Fick has advocated a modification of the original conception which, it was hoped, would obviate the difficulty. Fick posits a uniformity of structure for the whole retinal surface, but conceives that the function of the eccentric regions has undergone a peculiar modification. He still holds to the essential fea-

*Aubert's position with regard to this question is not altogether clear. The writer is convinced, however, that he has done no violence to the views of this noted investigator in the above summary statement of his position. 
tures of the Young-Helmholtz theory, and assumes that in direct vision every homogeneous stimulus excites all three sorts of visual substance, but excites each in a characteristically unequal degree. Thus red light stimulates the red-sensing substance most intensively, the green-sensing substance less intensively, and the blue-sensing substance least intensively; the curve which represents the intensity of excitation by red light will, therefore, reach its maximum in the red and will slope off gradually towards the blue. Green light stimulates the green-sensing substance most intensively, the red-sensing less, and the blue-sensing still less: in this case the curve has its crest in the green and slopes off to either side, more abruptly toward the blue. Now, Fick conceives that the relation of the intensities of excitation is wholly different upon the peripheral retina. Here the curves tend to flatten down to straight lines; all stimuli, of whatever color, here excite the different substances in equal degree. Thus it comes about that a red stimulus applied to the peripheral retina has a physiological effect similar to that produced in direct vision by white light. This assumption certainly makes it comprehensible why changes of color must occur in indirect vision, but that it enables one to understand why the phenomena reported by Bull and others should be observed can scarcely be maintained. Then, too, not only is Fick's explanation forced, but his assumption of a modified function of visual substance does violence to the essential principle of the theory which he advocates and defends.

Hering conceives that each of the visual substances which his theory assumes has a different retinal distribution. The white-black substance is distributed over the whole retina with approximate uniformity; while the other visual substances occur in decreasing quantity as we approach the periphery. Their relative distribution is such that any given region is less richly supplied with red-green than with blueyellow substance. If now it be assumed that in order to produce a constant physiological effect, the stimulation must be increased in proportion as the retinal supply of visual substance is relatively scant, the explanation of the phenomena of indirect vision becomes evident. The persistence upon the more eccentric regions of the retina, of gray after the specific color of the stimulus has disappeared, is referred to the presence at the periphery of black-white substance and the almost total absence at that region of color substance. The changes of color tone which occur in indirect vision are the result of a preponderance upon the peripheral retina of blue-yellow over red-green substance. Decrease of saturation is due to a relative increase of functioning upon more and more peripheral regions, of black-white substance. The coincidence of 
the limits of the pairs of zones is due to the fact that the same visual substance which gives rise to the sensation of red also produces the sensation of green, while the substance which furnishes the sensation of yellow also mediates the sensation of blue.

The present status of the problem may be summarized as follows: It has been established that color sensitivity decreases gradually from the center to the periphery of the retina; that every color stimulus is correctly recognized within a certain retinal zone, whose extent varies directly with the tone, the brightness (absolute and relative), the saturation, and the area of the stimulus, and with changing conditions of adaptation and of refraction; that under certain conditions the zone of a certain red is co-extensive with that of a green, while that of yellow is also co-extensive with that of blue; that the yellow-blue zone has a much wider extension than the red-green zone; that all colors, excepting the four mentioned above, pass through certain regular transitions of tone as they appear upon more and more peripheral regions of the retina; that these transitions tend in the direction of yellow (when red, orange, or green stimuli are employed) and blue (when violet stimuli are employed); and that with moderate stimulation all colors appear gray at the periphery, while with a sufficiently intensive stimulation, they may there appear in their own tones.

There are, in the opinion of the writer, two features of this general problem upon which it would be well to have additional light. It will be remembered that Hellpach reports the discovery of an extreme peripheral zone upon which all color stimuli tend to appear in their complementary colors. Since this phenomenon has been reported by no other investigator,* and since moreover it refuses to fit in with any of the color theories now in the field, it seems desirable to work over the ground covered by Hellpach with a view to discovering how his results are to be explained. Then, too, the coincidence of the pairs of zones which has been a characteristic of the findings of several recent investigators has in every case been established for the light-adapted retina alone. In view of the emphasis which in the recent literature is being laid upon the differences between the phenomena of light-adaptation and those of dark-adaptation, it seems distinctly worth while to determine whether this coincidence holds also for the dark-adapted retina.

* Since the above was written Peters obtained somewhat similar results in an exploration of the eccentric retina. 


\section{EXPERIMENTAL.}

The observers were all students of the Cornell Laboratory: Miss A. R. Jenkins, A. B. (J.) ; Miss J. B. Peirson (P.), Mr. C. E. Galloway, A. B. (G.), and Mr. H. C. Stevens, A. B. (S.) ; for their patient co-operation in a trying series of experiments the writer is grateful. The writer (B.) also gave a series of sittings, the apparatus being operated in this latter case by Miss Jenkins, or by a hired assistant. All of the observers are emmetropes, and all possess normal color vision.

The investigation followed two general lines of inquiry:

(I) The first group of experiments aimed to determine what changes of tone a color stimulus undergoes during the movement of its image across the retina. Here our sole concern was to find an answer to the question: What is the chromatic character of the sensation aroused when a constant color stimulus is applied successively to different regions of the retina?

(2) The second group aimed to determine the relative extension of the different retinal zones. Here our problem was: What is the relative extension of the retinal areas within which the tones of the different color stimuli are correctly recognized?

\section{CHANGES OF COLOR TONE IN INDIRECT VISION.}

A. Apparatus.

These experiments were conducted in the dark-room of the laboratory. This room was constructed for optical research, and was so arranged as to render possible any desired degree of illumination. During our experiments the room was in deepest darkness. The apparatus employed was the Hellpach perimeter. This was built to our order by Zimmermann, the Leipzig mechanician, and was in all its essentials an exact duplicate of the apparatus employed by Hellpach in a similar investigation.* It consists of a strong wooden frame about 1.5 meters long, from each end of which there rises a stout upright post. One of these posts is adjustable in height, and supports at its upper end a steel quadrant of $1 . I$ meter radius. The quadrant is attached to its support by means of an axis fitted into a bearing. This device enables the quadrant to turn freely, its complete revolution describing a hemisphere about a horizontal axis. The quadrant carries two lanterns of blackened brass, each containing an incandescent lamp of 16 candle power. One of these, the fixation-lantern, is made fast to the axis of the apparatus. The other, the stimulus-lantern, is attached to the quadrant by means of a metal clamp; it may be slid along the quadrant

*For illustration and description see Philosophische Studien, XV, 1900, S. 525ff. 
and securely clamped at any desired distance from the fixation-lantern; its distance from the eye of the observer therefore remains constant and equal to that of the fixation-lantern. The quadrant is graduated, so that the setting of the movable lantern may be read off conveniently. The quadrant also carries at its axis a graduated metal disc which rotates-with the rotation of the quadrant-under a stationary indicator; this device enables the experimenter to deternine exactly in what plane the quadrant stands at any given setting.

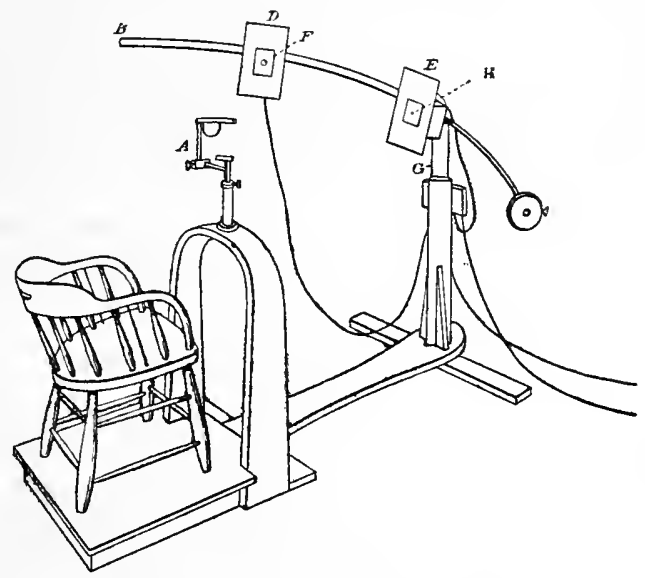

PERIMETER EMPLOFed IN PRESENT JNVESTIGation.

$A$, head-rest and eye-shield; $B E$, graduated steel quadrant with counter-weight; the quadrant revolves upon an axis at $\mathrm{E}$. $\mathrm{D}$, movable lantern carrying the stimulus-color; $\mathrm{E}$, stationary fixation-lantern; F, circular patch of stimulus-colo5; $\mathbf{H}$, fixation point. The quadrant revolves through $360^{\circ}$. It may be clamped and held securely upon any meridian which it crosses in the course of jts revolution. The stimulus-lantern may be clamped at any point upon the quadrant. This arrangement enables the experimenter to expose his stimulus-color at any point upon the surface of the hemisphere described by the quadrant.

The second upright carries an adjustable head-rest. This consists of padded supports for the chin and the forehead; it is also provided with a felt shield which screens the unused eye. At the beginning of each sitting the observer seated himself before the apparatus and adjusted the head-rest to the most convenient position. Then the height of the axis of the perimeter was so adjusted that the observer's eye was at the center of the hemisphere described by the rotating quadrant.

The two lanterns, although already encased in brass, were further inclosed in boxes of black cardboard, and the whole wrapped in several 
thicknesses of black cloth to prevent leakage of light. The cardboard front of the fixation-lantern was pierced by a circular aperture $5 \mathrm{~mm}$. in diameter. This point of light served as the fixation-object. Its yellowness was netutralized by the insertion of appropriate blue gelatines, and its brightness was reduced by the addition of white tissue papers. The luminosity of the fixation-point was slight, but it was well above the limen of perceptibility.

A circular apcrture $I_{5} \mathrm{~mm}$. in diameter was cut in the cardboard front of the stimulus-lantern. The color stimuli were produced by inserting immediately behind the plane of this aperture appropriate combinations of translucent sheets of colored gelatine. The light-stimulus transmitted through the gelatines could be controlled at will, in brightness, in saturation, and in color tone, by an appropriate choice of the gelatines which constituted the combination.

It was intended, at the outset, to reproduce exactly the experimental conditions employed by Hellpach. This plan, unfortunately, proved to be impracticable, for the reason that Hellpach's descriptions are so vague and inaccurate as to render an exact duplication of his experiments impossible. For example, instead of making a direct statement of the wave-lengths of his color stimuli, he gives the positions of the Frauenhofer lines in his spectrum, and the scale-readings which he obtained in the spectroscopic examination of his stimuli. It should, of course, be a simple matter to chart his spectrum from the former data, and by a method of graphic interpolation to obtain a regular curve which would enable us to correlate the scale-readings of his stimuli with the wave-lengths which enter into their composition. But Hellpach's data refuse to submit to being charted. Instead of giving a regular curve which sweeps down with approximately constant change of direction from the red to the violet, they give an inpossible figure, shaped somewhat like an elongated $\mathrm{W}$, with its central crest lying in the region of the $\mathrm{E}$ and $b$ lines. It is impossible to determine with any degree of definiteness the height of any intermediate point upon this irregular curve. One is unable, therefore, to discover, from his data, what were the wave-lengths of the stimuli employed in his experiments.*

Since we were balked in our attempt to duplicate Hellpach's colors,

*The values which Hellpach reports for the positions of his Frauenhofer lines are clearly erroneous. And since the spectral determinations of his stimuli refer to these erroneously determined constants, the data contained in his paper furnish no definite information as to the wave-lengths of his color-stimnli. It is true that in one case-that of his yellow stimulus-he records his spectral determination in unequivocal terms. But the testimony of Peters, and our own experience with this stimulus, show that here, too, Hellpach has made a false deternination. 
we chose as our stimuli six tones which represent more or less widely separated parts of the spectrum, and added to these a purple. The reproduction of these seven tones by means of combinations of gelatines was not always an easy task. But if the supply of gelatines at hand contains a sufficient variety of tones and of saturations, one readily acquires skill in choosing and combining them, and the desired results may be obtained by the exercise of persevering effort.

We set up a spectroscope in the room where the experiments were conducted and made a spectroscopic examination of each combination of gelatines before it was finally selected as a color stimulus. It is, of course, essential that this examination be made under the same conditions as are to be employed in the exploration experiments. The light emitted by the stimulus-lantern was not white, but of a distinctly yellow tone. This yellowness must be taken into account, and must be neutralized by means of appropriate blue gelatines, in the reproduction of the color stimuli. It is, then, essential, for an obvious reason, that the source of light which is to be employed in the experiments themselves should also be employed in the spectroscopic examinations.

Hellpach found that no combination of the gelatines to which he had access gave a satisfactory yellow stimulus. He was therefore led to employ a light filter of another form. This consisted of two cylindrical cells of glass, which were placed end to end before the stimuluslantern. The larger cell was filled with a six per cent solution of dichromate of potassinm, the smaller with a five per cent solution of deep-green urano-sulphate, which had been obtained by reducing yellow uranyl-sulphate. We are told that the light transmitted through these solutions proved to be exactly what Hellpach required for his experiment. Not only was it a good yellow; it was also monochromatic. "Im Spcktroskop ist dann bei Anwendung weissen Lichtes das ganze Spcktrum bis auf dic gclbc Na-Linic total ausgclöscht." Phil. Stur., XV, S. 530.) One is tempted to wonder why Hellpach employed white light in this spectroscopic examination. The source of light which he chose for his experiments in retinal exploration was not white, but yellow. If, as this statement seems to indicate, Hellpach employed white light in all of his spectroscopic examinations, it is clear that the color stimuli actually employed in his investigation were not submitted to a spectroscopic examination at all. One is also led to wonder why, since his liquid filter gave him monochromatic light, he did not employ it, with a changed content, of course, in the production of his other color stimuli. He certainly succeeded in no other case, in even approximating monochromatic light. (See his table, l. c., S. 529.) 
We have wholly failed to obtain satisfactory results from Hellpach's liquid filter. Our cells were duplicates of those employed by Hellpach—both were manufactured by Zimmermann-and our solutions were prepared in accordance with Hellpach's description by Dr. Hector R. Carveth, of the Department of Chemistry in Cornell University. Every care was taken to duplicate the conditions exactly as described by Hellpach, but a wholly different result was obtained. The light transmitted through the solution was not yellow, but orange; its spectroscopic examination showed it to contain red (694 $\mu \mu$ to 673 $\mu \mu)$ and a band extending through the orange, yellow, and yellow-green (6I8 $\mu \mu$ to $573 \mu \mu$ ). So that while it contained spectral yellow of the sodium line, it contained many other colors besides. And its appearance was so distinctly orange as to render it valueless as a yellow stimulus.*

In the building up of our color stimuli we followed the same general method as was adopted by Hellpach. Our red, orange, green, blue, violet, and purple stimuli were obtained by means of colored gelatines. Our yellow was obtained by adding to Hellpach's filter a combination of red, green, blue, and violet gelatines, which cut down the spectral band to orangish-yellow. The following table shows the chromatic constituents of each of our stimuli, the spectroscopic examination being made, in every case, by means of light from the stimulus-lantern:

\begin{tabular}{|c|c|c|}
\hline $\begin{array}{l}\text { Number of } \\
\text { color stimulus. }\end{array}$ & $\begin{array}{l}\text { Its appearance in } \\
\text { direct vision. }\end{array}$ & $\begin{array}{l}\text { Spectral brand transmitted } \\
(\text { expressed in } \mu \mu) .\end{array}$ \\
\hline $\begin{array}{l}1 \ldots \ldots \cdots \cdots \\
2 \ldots \ldots \cdots \cdots \\
3 \ldots \ldots \cdots \cdots \\
4 \ldots \ldots \cdots \cdots \\
5 \ldots \ldots \cdots \cdots \\
6 \ldots \ldots \cdots \cdots\end{array}$ & $\begin{array}{l}\text { Deep red ......... } \\
\text { Reddish orange... } \\
\text { Orange yellow.... } \\
\text { Green ............. } \\
\text { Blue............. } \\
\text { Violet........... } \\
\text { Pnrple......... }\end{array}$ & $\begin{array}{c}706-631 \\
640-592 \\
619-581 \\
546-522 \\
519-642 \\
493-431 \\
\text { Red end of spectrum-682 }\end{array}$ \\
\hline
\end{tabular}

The results given in the third column indicate the extreme edges of the band of spectral light which was visible in the spectroscope when the combination of gelatines was held before the slit. The edges of this band were extremely indistinct at the points where our readings were taken; and the color was finally lost in the surrounding blackness. Our scale readings, which we have translated into wave-lengths, were taken for the outer limits of visibility. It is probable, therefore, that

*It is interesting to note in this connection that Hellpach reponts that the sensation of yellow is absent from indirect vision. He finds, as one might expect, that this orange stimulus is perceived as orange upon the paracentral regions of the retina. 
the physiological effects of these edges were sub-liminal, and that the stimuli which were actually operative physiologically in our experiments represent narrower bands than we have given in the table.

\section{B. METHOD.}

In these experiments only the horizontal meridian, nasal and temporal, was explored. Each sitting was preceded by fifteen minutes' adaptation in absolute darkness. The exploration began at the periphery and was continued to the paracentral region, within $10^{\circ}$ of the center of the fovea. The method employed was a procedure without knowledge. In no case did the observer know what stimulus was to be employed; in no case did he see it in direct vision until after the series had been completed.

After the adaptation period had elapsed, the lights were turned on in the two lanterns, and the observer was asked to fixate. .The stimulus color was still invisible, since it was hidden by a shutter. When accurate fixation had been secured, signals were exchanged, and the stimulus color was exposed for a period of three seconds. Then the lights were turned off, the observer's record was taken, and the stimulus-lantern was moved to a position ten degrees nearer the fixation-point. After a rest of six or seven minutes the experiment was resumed, as before. The three seconds' period of exposure was at first marked off by a metronome, but it later became possible to estimate the period from memory with a high degree of accuracy. The subject wrapped his head in a heavy cloth while the readings were being taken and the stimuluslantern was being moved to its new position. The readings and settings were made by the light of a portable electric lamp (the pocket flashlight). This lamp was found to be exceedingly convenient, and admirably suited to dark-room experiments.

The earlier records are not included in our published results. Some time was lost in practice before the observers acquired the power to maintain an accurate fixation during the exposure of the color. It was found, too, that in our earlier experiments the interval of rest which elapsed between consecutive exposures was too short. After a good deal of experimentation it was decided that six minutes was about the optimal interval of rest, under our experimental conditions. A shorter interval could not be employed for reasons which will be discussed later.

For the sake of control each meridian was explored twice, at different sittings. During the first exploration the stimulus-lantern was set successively at $90^{\circ}, 80^{\circ}, 70^{\circ}$, etc.; during the second, it was set at intervening positions, $85^{\circ}, 75^{\circ}, 65^{\circ}$, etc. In our tabulated records we have combined the results of each pair of explorations into a single series. 
Each exploration was carried through with three different luminosites of stimulus. Inasmuch, however, as the intermediate luminosity revealed no characteristic features, we shall append only the data obtained from the maximal and minimal stimuli.

Before the exploration of the retina was begun the observers were submitted to an examination in the naming of colors. Each was asked to describe the colors corresponding to certain scale-readings in the spectroscope and to state the position of the most characteristic tone of each of the colors. As a result of this examination, a high degree of uniformity in the employment of color names was attained. During the course of the experiments the observers were asked to characterize their color sensations as definitely as possible. Thus the observer who reported a green sensation was required to state whether he saw a characteristic green or a green which inclined toward yellow or toward blue, whether it contained a small or a large admixture of yellow (or blue), etc. Every precaution was taken to have the color sensations described as accurately and as definitely as possible.

\section{Gross Results.}

Tables I, 2, 3. and 4 contain a general statement of the results yielked by the experiments just described. Tables $\mathbf{I}$ and 2 give the results obtained by means of the seven stimuli of relatively high intensity, while the results tabulated in 3 and 4 were obtained with the same color stimuli in lesser intensity. The results obtained in the exploration of the nasal half of the horizontal meridian of the retina will be found in Tables 1 and 3 : those obtained from the temporal half of the same meridian are given in Tables 2 and 4 .

The results as set down in the tables are grouped by stimuli; thus, the upper section of each table records the sensations reported by each observer (B, G, J, P, and S) on the application of the red stimulus (R).

The numbers in the table express the degree of eccentricity (in degrees) of the stimulus, when each judgment was reported. The colors reported are indicated by the initials ( $R$, red; $O$, orange; etc.), excepting in case of slight saturation, where the color name with its suffix is written out in full. Pairs of initials indicate judgments of composite colors, the second letter referring to the stronger component; thus, OR means a red, containing a tinge of orange. In a few cases the observer reported the presence of a color which was not sufficiently distinct to be identified; judgments of this sort are indicated by a question mark (?). The color-initial $\mathrm{G}$ always signifies green; when gray is meant the name appears in full. 
TABLE 1.-Bright stimulus.-Nasal half of horizontal meridian of retira.

\begin{tabular}{|c|c|c|}
\hline & & Degree of eccentricity of stimulus; and color reported by observer. \\
\hline R. & $\begin{array}{l}\text { B. } \\
\text { G. } \\
\text { J. } \\
\text { P. } \\
\text { S. }\end{array}$ & $\begin{array}{l}\text { All observers recognized this stimulus as red, even at the ex- } \\
\text { treme periphery }\left(90^{\circ}\right) \text {. Saturation increased with increase } \\
\text { of distance from periphery. There was reported in most } \\
\text { cases a slight change of color tone, the red inclining less } \\
\text { towards orange as the fovea was approached. }\end{array}$ \\
\hline$\stackrel{\text { o. }}{\text { [RO.] }}$ & $\begin{array}{l}\text { B. } \\
\text { G. } \\
\text { J. } \\
\text { P. } \\
\text { S. }\end{array}$ & 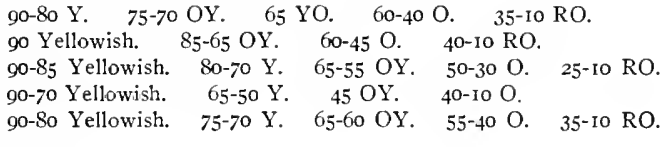 \\
\hline Y.ं.] & $\begin{array}{l}\text { B. } \\
\text { G. } \\
\text { J. } \\
\text { P. } \\
\text { S. }\end{array}$ & $\begin{array}{l}\text { This stimulus was itvariably jecognized as yellowish or yellow } \\
\text { at the extreme periphery }\left(90^{\circ}\right) \text {. It increased in saturation } \\
\text { and assumed an orangish tint toward the center of the retina. }\end{array}$ \\
\hline G. & $\begin{array}{l}\text { B. } \\
\text { G. } \\
\text { J. } \\
\text { P. } \\
\text { S. }\end{array}$ & 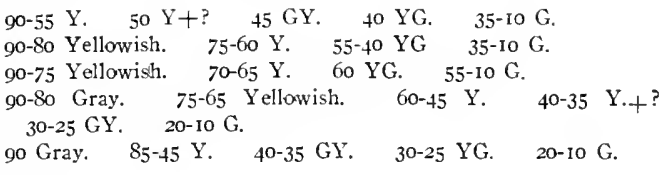 \\
\hline B. & $\begin{array}{l}\text { B. } \\
\text { G. } \\
\text { J. } \\
\text { P. } \\
\text { S. }\end{array}$ & $\begin{array}{l}\text { All observers saw this stimulus as bluish from the first. There } \\
\text { was a distinct increase in saturation. No change in color } \\
\text { tone was perceptible. }\end{array}$ \\
\hline V. & $\begin{array}{l}\text { J. } \\
\text { P. } \\
\text { S. }\end{array}$ & 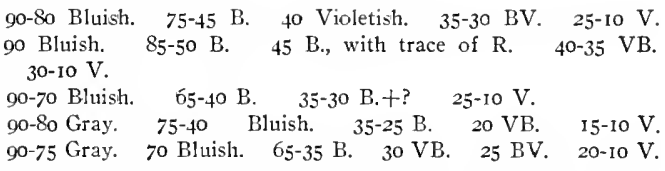 \\
\hline P. & $\begin{array}{l}\text { B. } \\
\text { G. } \\
\text { J. } \\
\text { P. } \\
\text { S. }\end{array}$ & 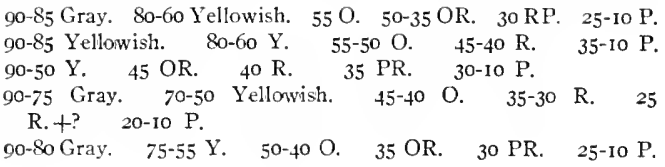 \\
\hline
\end{tabular}




\section{COLOR SENSITIVITY OF THE PERIPHERAL RETINA.}

TABLE 2.-Bright stimulus.-Temporal half of horizontal meridian of retina.

\begin{tabular}{|c|c|c|}
\hline $\begin{array}{c}\text { Color } \\
\text { of } \\
\text { stimulus. }\end{array}$ & $\left|\begin{array}{c}\text { Initial } \\
\text { of ob- } \\
\text { server. }\end{array}\right|$ & Degree of eccentricity of stimulus; and color reported by observer. \\
\hline R. & $\begin{array}{l}\text { B. } \\
\text { G. } \\
\text { J. } \\
\text { P. } \\
\text { S. }\end{array}$ & $\begin{array}{l}60 \text { Gray. } 55-50 \text { Reddish. } 45-10 \mathrm{R} . \\
55 \text { Gray. } 50 \text { Reddish. 45-10 R. } \\
60-55 \text { Gray. } 50-45 \text { Reddish. 40-10 R. } \\
60-55 \text { Gray. } 50 \text { Yellowish. } 45 \text { Y. 40-30 OR. } \\
55 \text { Yellowish. } 50-45 \text { Orangish. } 40 \text { O. } 35-0 \mathrm{R} .\end{array}$ \\
\hline ORO.] & $\begin{array}{l}\text { B. } \\
\text { G. } \\
\text { J. } \\
\text { P. }\end{array}$ & 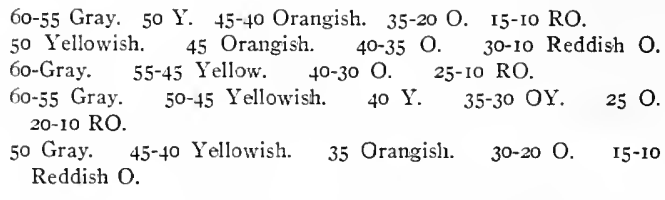 \\
\hline [OY.] & $\begin{array}{l}\text { B. } \\
\text { G. } \\
\text { J. } \\
\text { P. } \\
\text { S. }\end{array}$ & 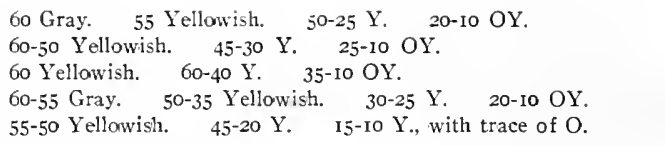 \\
\hline G. & $\begin{array}{l}\text { B. } \\
\text { G. } \\
\text { J. } \\
\text { P. } \\
\text { S. }\end{array}$ & 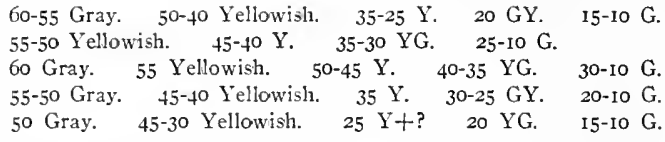 \\
\hline B. & $\begin{array}{l}\text { B. } \\
\text { G. } \\
\text { J. } \\
\text { P. } \\
\text { S. }\end{array}$ & 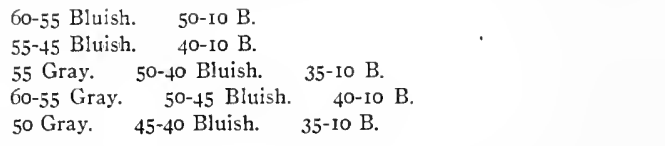 \\
\hline V. & $\begin{array}{l}\text { B. } \\
\text { G. } \\
\text { J. } \\
\text { P. } \\
\text { S. }\end{array}$ & $\begin{array}{lcccc}\text { ó-55 Gray. } & \text { 50 Bluish. } & 45-35 \mathrm{~B} . & 30-25 \mathrm{~B} .+ \text { ? } & \text { 20-1o V. } \\
\text { 50-40 Bluish. } & 35-30 \mathrm{~B} . & 25-\mathrm{IO} \mathrm{V} . & & \\
\text { 50 Gray. } & 45-35 \text { Bluish. } & 30 \mathrm{~B} . & 25 \mathrm{VB} . \quad 20 \mathrm{~V} . \\
60-55 \text { Gray. } & 50-35 \text { Bluish. } & 30-20 \mathrm{~B} . & \text { I5 BV. } & \text { Io V. } \\
55-50 \text { Gray. } & 45-30 \text { Bluish. } & 25 \mathrm{~B} . & 20 \mathrm{~B}+? & 15-10 \mathrm{~V} .\end{array}$ \\
\hline P. & $\begin{array}{l}\text { B. } \\
\text { G. } \\
\text { J. } \\
\text { P. } \\
\text { S. }\end{array}$ & 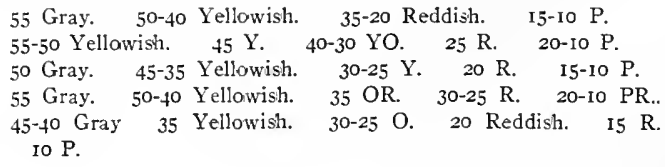 \\
\hline
\end{tabular}


COLOR SENSITIVITY OF THE PERIPHERAL RETINA. 5 I

TABLE 3.-Weak stimulus.-Nasal half of horizontal meridian of retina.

\begin{tabular}{|c|c|c|}
\hline $\begin{array}{l}\text { Color } \\
\text { of } \\
\text { stimulus. }\end{array}$ & & Degree of eccentricity of stimulus; and color reported by observer. \\
\hline R. & $\begin{array}{l}\text { J. } \\
\text { P. } \\
\text { S. }\end{array}$ & 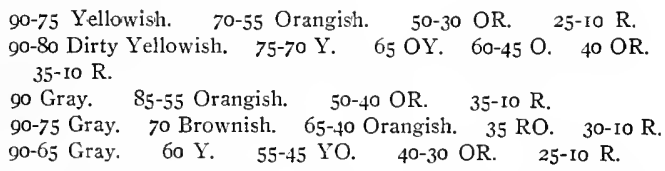 \\
\hline ORO.] & $\begin{array}{l}\text { B. } \\
\text { G. } \\
\text { J. } \\
\text { P. } \\
\text { S. }\end{array}$ & 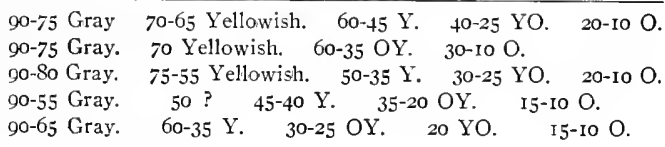 \\
\hline & $\begin{array}{l}\text { B. } \\
\text { G. } \\
\text { J. } \\
\text { P. } \\
\text { S. }\end{array}$ & 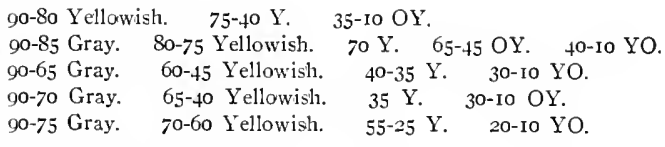 \\
\hline G. & $\begin{array}{l}\text { B. } \\
\text { G. } \\
\text { J. } \\
\text { P. } \\
\text { S. }\end{array}$ & 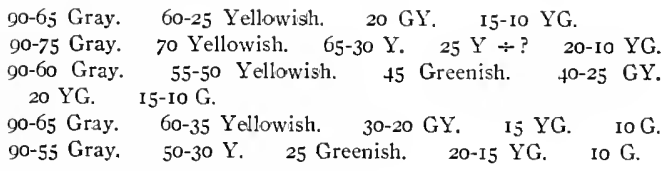 \\
\hline B. & $\begin{array}{l}\text { B. } \\
\text { G. } \\
\text { J. } \\
\text { P. } \\
\text { S. }\end{array}$ & 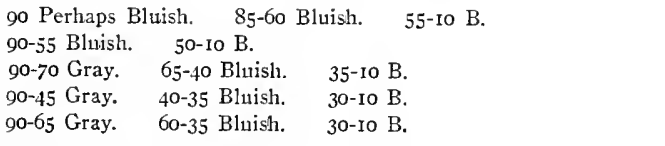 \\
\hline V. & $\begin{array}{l}\text { B. } \\
\text { G. } \\
\text { J. } \\
\text { P. }\end{array}$ & 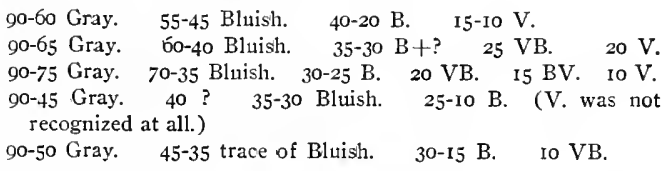 \\
\hline P. & $\begin{array}{l}\text { G. } \\
\text { J. } \\
\text { P. } \\
\text { S. }\end{array}$ & 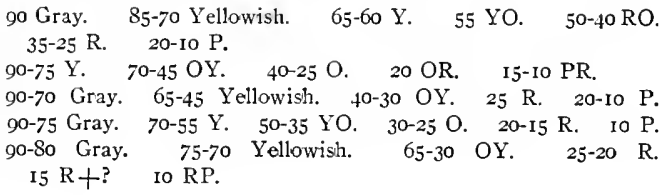 \\
\hline
\end{tabular}


TABLE 4-Weak stimulus.-Temporal half of horizontal meridian of retina.

\begin{tabular}{|c|c|c|}
\hline $\begin{array}{c}\text { Color } \\
\text { of } \\
\text { stimulus. }\end{array}$ & $\left|\begin{array}{c}\text { Initial } \\
\text { of ob- } \\
\text { server. }\end{array}\right|$ & Degree of eccentricity of stimulus; and color reported by observer. \\
\hline R. & $\begin{array}{l}\text { B. } \\
\text { G. } \\
\text { J. } \\
\text { P. } \\
\text { S. }\end{array}$ & 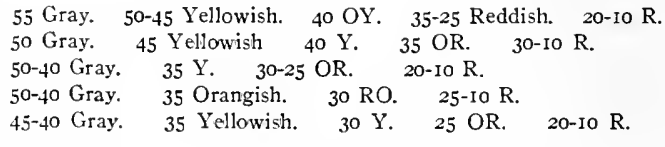 \\
\hline O. & $\begin{array}{l}\text { B. } \\
\text { G. } \\
\text { J. } \\
\text { P. } \\
\text { S. }\end{array}$ & 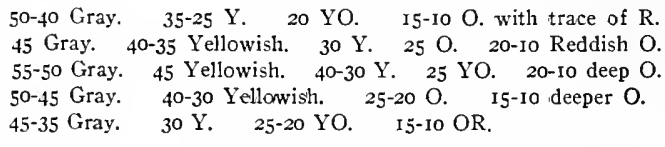 \\
\hline Y. & $\begin{array}{l}\text { B. } \\
\text { G. } \\
\text { J. } \\
\text { P. } \\
\text { S. }\end{array}$ & 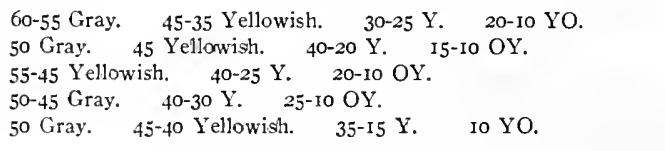 \\
\hline G. & $\begin{array}{l}\text { B. } \\
\text { G. } \\
\text { J. } \\
\text { P. } \\
\text { S. }\end{array}$ & $\begin{array}{l}\text { 50-30 Yellowish. 25-20 Y. I5 YG. Io G. } \\
\text { 55-50 Gray. 45-35 Yellowish. } 30-25 \mathrm{GY} \text {. 20-10 G. } \\
55 \text { Gray. 50-40 Yellowish. } 35-25 \mathrm{Y} \text {. 20-10 G. } \\
45 \text { Yellowish. } 40-20 \text { Y. I5 YG. 10 G. } \\
45 \text { Gray. 40-20 Y. I5-I0 G. }\end{array}$ \\
\hline B. & $\begin{array}{l}\text { B. } \\
\text { G. } \\
\text { J. } \\
\text { P. } \\
\text { S. }\end{array}$ & 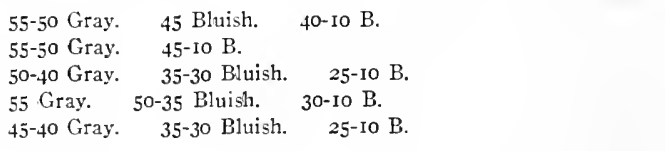 \\
\hline V. & $\begin{array}{l}\text { B. } \\
\text { G. } \\
\text { J. } \\
\text { P. } \\
\text { S. }\end{array}$ & 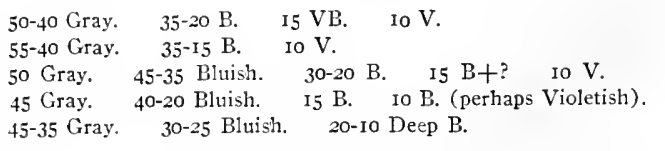 \\
\hline P. & $\begin{array}{l}\text { G. } \\
\text { J. } \\
\text { P. } \\
\text { S. }\end{array}$ & 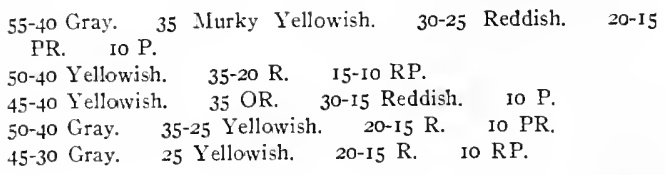 \\
\hline
\end{tabular}


SUMMIARY OF GROSS RESULTS.

These experiments show that, with slight luminosity of stimulus, all colors appear colorless at the periphery of the retina; that when they are brought in far enough to appear colored, those of the red-end of the spectrum first appear yellowish or yellow, while those of the blue-end first appear bluish or blue; and that in assuming their proper tones they pass through a regular series of transitions. These transitions were so pronounced that all observers were surprised to find that a constant color stimulus could appear in such widely different tones. Indeed, it frequently happened that an observer refused to believe that the objective conditions of stimulation had remained constant throughout the series. The changes of color tone reported were:

(I) Red first appeared yellowish, then passed through yellow, orangish-yellow, yellow-orange, orange, and orange-red before it finally appeared red.

(2) Orange came in yellowish, gradually assumed a more and more orangish tint, and finally appeared orange or reddish-orange.

(3) Yellow first appeared yellowish, gradually increased in saturation, and became orangish towards the center of the retina. This stimulus really contained an orangish tint.

(4) Green appeared yellowish at first, gradually increased in saturation, and towards the close of the series assumed a greenish, and finally a green tint.

(5) Blue underwent no appreciable change of tone, but became more and more saturated as the series progressed towards the fovea.

(6) Violet appeared bluish, then blue, and took on a violet tint very much later. Indeed, it sometimes happened that the violet tone of this stimulus was not recognized at ten degrees from the visual axis.

(7) Purple gave the longest and richest series of transitions. Beginning with yellowish, its tone gradually moved down the spectrum, passing through orange-yellow, yellow-orange, orange, orange-red, red, purplish-red, and reddish-purple, before the pure tone of the stimulus finally appeared.

A comparison of the two sets of results (obtained with different luminosity of stimulus) shows that the retinal zones of sensitivity expand with increase of intensity of stimulation. To what degree this expansion may be brouglit about by appropriate variation of stimulus can not be decided definitely from these experiments. Yet it seems safe to infer that if the stimulation be sufficiently intensive, all colors may be recognized at the extreme periphery. Indeed, an attempt was made in a series of subsidiary experiments to test the validity of the ExnerLandolt principle. When the luminosity of the stimuli was increased it 


\section{COLOR SENSITIVITY OF THE PERIPHERAL RETINA.}

was found that orange, green, and purple were perceived in their true colors at $90^{\circ}$ on the nasal retina ; violet was sometimes reported as violet, but usually as violetish-blue even when the maximal luminosity available was employed. There seems no room for doubt, however, that had we been able to brighten our violet stimulus sufficiently it, too, would have been recognized at the periphery.

It should be borne in mind that the stimuli employed in these experiments were equated neither in white-value nor in color-value. Hence our results justify no conclusion as to the relative extension of the different retinal zones. (See p. 62.)

\section{Detailed Statement of Results.}

Besides the features already described, two other phenomena of indirect vision were reported by all five observers. These may be described as: (a) Progressive changes in the saturation and in the color-tone of the sensation which results from continuous stimulation, and $(b)$ variations of saturation and of color-tone which result from changed conditions of the local chromatic adaptation of the retina.

(a) Progressize changes of saturation and of color tone which occur during the continuous application of a constant stimulus.

It was discovered during these experiments that however constantly and continuously the peripheral stimulus be applied, the sensation which it arouses is neither constant nor continuous. Not only was there a marked decrease in the saturation, and sometimes in the brightness of the sensation during the progress of the stimulation, but there frequently occurred a pronounced change in its color-tone as well. The matter can best be described by saying that each sensation consisted of a series of more or less different phases, which ran their course during the process of stimulation. The detailed records which follow show the characteristics of these series. In the results which are set down in Tables I, 2, 3, and 4 only the first chromatic phase of each series is recorded. The succeeding phases are to be described in this section. The following are typical records selected more or less at random from a great number, which can not, of course, be given in their entirety:

Simulus R.-Lantern set at 5o. At the first moment of exposure RO. appeared, which changed immediately to $O$. This was followed by $Y$., which became yellowish, and so persisted until the end of the exposure. (It is to be remembered that these changes appeared in the presence of an unohanging objective stimulus, and during the process of stimulation. The duration of each series of phases recorded was three seconds, $i$. $e$., was coincident with the period of stimulation. The phases were so evanescent that it frequently seemed impossible to make any definite statement as to the duration of each. However, the observers were asked to estimate the relative durations, and where they succeeded in doing so, their reports are indicated by fractions set down after 
each phase estimated. Thus, OY. $1 / 8-Y . x / 2-W$. indicates that the first phase lasted about one-eighth of the three-second period, and the second phase persisted for about half of the period; the W. phase occupied the remainder of the three seconds.)

40. RO.-YO.-Gray.-B. (The B. was slightly longer than any other phase.)

30. R.-O.-Y.-W.-B. (The blue phase persisted longer than any other.)

2o. R.-RO.-Y.-Gray.

Io. R. $2 / 3 .-\mathrm{O} .-\mathrm{Y} .-\mathrm{Y}$ ellowish-gray.

Stimulus Y.-6o. Y $1 / 6 .-W$.

50. $Y .1 / 4 .-W$.

40. Y.1/4.-W.-Bluish.

30. OY.-Y.-Gray-Bluish. (Y. had the best saturation.)

20. OY. $1 / 8 .-Y .1 / 2 .-W$.

Stimulus O.-9o. Y.-Yellowish.-Gray $1 / 4$.

8o. OY.-Y.-Gray.

7o. OY.-Y.-Yellowish.

6o. YO. $1 / 2 .-Y .-Y$ - Ylowish-gray.

50. YO. $1 / 2,-O Y .-Y .-G r a y$.

40. O.1/2.-OY.-Y.-Gray.

30. Rich O.-YO.-Y.

2o. RO.-O.-OY.-Y.

Io. RO. $2 / 3,-Y$.

Stimulus G.-85. Gray. No change.

75. Yellowish.-Gray.

65. Y.-Gray.-Bluish.

55. Y.-Gray.-Pale Bluish.

45. Y.-Gray.

35. Y.-Brownish-Gray--Bluish.

25. YG.-Y.-Gray.-Bluish.

15. G. $-\mathrm{YG}$.

Sirmulus B.-9o. Gray. No change.

8o. Gray. No change.

7o. Gray. No change.

6o. Bluish.-Gray.

5o. Bluish.-Gray.

40. B.-Bluish.-Gray.

30. B. $1 / 2$. - Gray.-Yellowish.

20. B. $1 / 2 .-$ Gray. Slow and gradual decrease of saturation.

10. B. $2 / 3 .-$ Bluish-gray. Slow and gradual decrease of saturation.

Strmulus V. $\rightarrow$ o. Gray. No change.

So. Gray. No change.

7o. Gray. No change.

6o. Gray.-Darker Gray.

5o. Bluish.-Gray.

40. Bluish.-Gray.

3o $\mathrm{B}+$ ?.-B.-Bluish.

20. VB. $1 / 3 .-$ B. - Bluish.

Io. V.-VB.-B.

Stimulus P. 85. Gray. No change.

75. Yellowish.-Gray.

65. OY.-Yellowish.-Gray.

55. OY,-Yellowish.-Gray.

45. OY.-Y.-Yellowigh.

35. OR.-O.-Y.

25. R.-OR.-Orangish.

I5. P.-R.-Orangish. 
A surver of these results reveals the presence in indirect vision of two general directions of change of sensation during the period of stimulation. One of these is a change of saturation; the other has to do with color-tone. Changes of brightness were reported in only a few instances. However well saturated the color may appear at the first instant of exposure, it tends to fade out as the exposure continues, and finally to become gray. In the above results it will be seen that the persistence of color was much greater upon paracentral than upon peripheral regions. In the latter case, the saturation is nuch less deep in the initial phase, and the color frequently fades so rapidly that it appears but as a momentary flash. On the paracentral regions, however, the color frequently persisted in sufficient saturation to be recognized, during the whole period of exposure. Besides the degree of eccentricity the color-tone of the stimulus seems to have an influence upon the persistence of the saturation. It will be noticed that yellow and blue paled out much less rapidly than did the other colors; while, under the conditions of our experiments at least, violet and purple changed most rapidly. Still another point is to be noted in this connection. The series did not always terminate when the gray phase was reached, but frequently passed over into the complementary of the ante-gray phase. The variety of colors apearing in the complementary phase is therefore limited to two-blue and yellow.

The variations of color-tone are no less pronounced than are those of saturation. Here the tendency is to change in the direction of yellow or blue; thus colors of the red-end of the spectrum, including our purple and our green stimulus, successively pass through those tones which separate them in the spectrum from the yellow and finally appear yellow, while the violet passes over into blue. Fron that point on, their sole change is, as described above, a more or less gradual loss of saturation and a subsequent passage into the complementary blue or yellow.

There is reason to believe that the whole chromatic series described above may be preceded, at the first instant of stimulation, by a phase of gray. This phase was occasionally reported in our experiments, but it was never present for more than the briefest period of time. It was more frequently seen with blue than with any other stimulus. In nearly all other cases it was either wholly lacking or it was so brief and fleeting that its presence could not be affirmed with any degree of assurance.

After-images-in the ordinary sense of the term-were almost invariably absent from our experiments. They were reported in less than one per cent of our exposures; and when they did occur, they were 
aroused by the stimulation of paracentral, never of peripheral, regions of the retina.

A comparison of the different series of phases tabulated above leads one to believe that in many instances the series had not run its complete course when the stimulation ceased. And this is particularly true of the more central regions of the retina. It seems probable that the time required for the complete chromatic adaptation (or fatigue) of a given region varies with its distance from the fovea.

(b) Variations of saturation and of color tonc which result from changed conditions of the local chromatic adaptation of the retina, i. c., which occur as the rcsult of previous stimulation.

If in a series of experiments upon the peripheral retina, the time interval elapsing between successive stimulations be brief, a characteristic phenomenon appears. Instead of sensations which correspond in tone with the objective stimulus, or with such transitions as have been described above, the observer will report phenomena which seem, at first sight, to be of the most irregular and accidental character. The nature of this change of sensation is evident from the following table. The experimental conditions under which these results were obtained were identical with those already described, excepting that the interval between successive exposures was here reduced to one minute or less. Each group of results in the table represents a series of stimulations of the horizontal meridian of the nasal retina, applied at the degrees of eccentricity indicated. The settings of the stimulus-lantern were made in irregular order; but in every case the same order has been preserved in setting down the results. Here again we have chosen but a few of the typical series from a large number of similar character.
R. 85 Gray.
75 Yellowish.
65 Yellowish.
55 Yellow.
45 Bluish.
35 Blue.
75 Blue.
85 Bluish.

O. 80 Yellowish.

7o Yellow.

60 Yellow.

5o Bluish.

40 Blue.

8 Bluish.

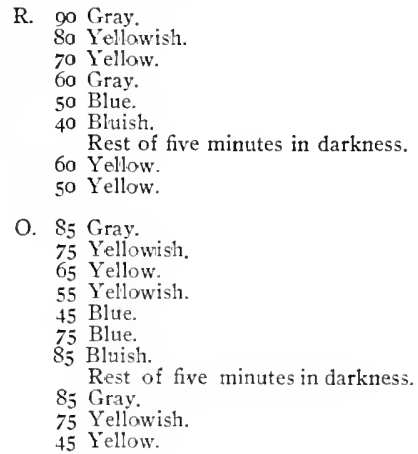


Y. 80 Gray.

70 Yellowish.

60 Yellow.

50 Yellow.

7o Blue.

80 Bluish.

G. 65 Gray.

55 Yellow.

45 Bluish.

35 Blue.

65 Blue.

B. 65 Bluish.

60 Bluish.

55 Blue.

50 Gray.

45 Yellow.

65 Yellow.

6o Yellow.

V. \&o Gray.

70 Gray.

60 Bluish.

50 Blue.

40 Blue.

So Yellowish.

70 Yellowish.

P. 85 Gray.

75 Gray.

65 Yellowish.

55 Bluish.

45 Blue.

85 Blue.

75 Bluish.
Y. 65 Yellowish.

55 Yellow.

45 Blue.

35 Blue.

Rest of five min utes in darkness.

35 Yellow.

45 Yellow.

G. 60 Yellow.

50 Yellowish.

40 Blue.

30 Blue.

20 Bluish.

Io Green.

Rest.

40 Yellow.

30 Yellow.

G. 40 Yellowish.

35 Green.

30 Reddish.

25 Reddish.

Rest.

30 Green.

Rest.

25 Green.

B. 65 Gray.

55 Bluish.

45 Blue.

35 Bluish.

25 Yellow.

Rest.

35 Blue.

25 Blue.

V. 55 Blue.

45 Blue.

35 Gray+?.

25 Yellow.

Rest.

35 Blue.

25 Blue.

P. 60 Yellow.

50 Yellow.

40 Grayish.

30 Bluish.

20 Blue.

Io Violetish Purple.

Rest.

40 Orange.

30 Orange Red.

Rest.

2o Purple Red.

Io Purple.

That the appearance of the complementary color in these experiments is wholly due to a failure to maintain a constant condition of retinal adaptation, there can be little doubt; for the irregularity invariably disappears when the eye is rested for a time in complete darkness.

A surprising fact in connection with these after-effects was the observer's utter ignorance of their existence. They were not attended by after-images nor by any other conscious datum. Pauses were frequently made and the observer was asked to be on the lookout for 
after-images, but he invariably reported that no visual phenomenon of any sort was present to consciousness, after the cessation of the stimulus. We can only conclude that the functioning of the peripheral retina is followed by an after-effect which is tenaciously persistent and is wholly latent in character; and that this sub-liminal capacity is called into active functioning by subsequent stimulation.

Just how extensive, spatially, is the domain of influence of the aftereffect is not shown by our experiments. That it is less circumscribed than the retinal image which occasions it seems, however, evident. One may infer that its extension is a function of the intensity and duration of the stimulus, and possibly of other factors as well. A few experiments devised for the purpose of determining in a general way the extent of its influence gave results which seem to indicate that with a bright stimulus and a long exposure the after-effect may extend over the whole retinal surface.

\section{THE RELATIVE EXTENSION OF THE DIFFERENT RETINAL ZONES.}

These experiments aimed to determine what extent of retinal surface is sensitive to a certain red, to a certain yellow, to a certain green, and to a certain blue. The colors here employed as stimuli were those which undergo no change of tone in indirect vision.

It is evident from the foregoing experiments ( $p .53 \mathrm{f}$.) that a retinal zone is not a fixed but a variable quantity; that its limits may be varied at will by an appropriate variation of the conditions of experimentation. It is therefore essential that an investigation which hopes to yield comparative data regarding the variable limits of the retinal zones should provide means for the accurate control of all of the determinant factors, and for the variation of but a single factor at a time during the progress of the experimentation.

\section{A. Apparatus.}

The apparatus employed in these experiments was identical with that already described (p. $42 \mathrm{ff}$.), but the stimuli employed in the present case were stable colors; and they were equated both in white-value and in color-value. The first preliminary to the investigation was the establishing of the stable colors. This was accomplished by passing various color stimuli across the retina, and choosing those which underwent no change of tone. This was a comparatively simple problem in the case of the blue and the yellow, but it proved to be exceedingly difficult to find a red and a green which fulfilled the conditions required. It was 
easy to determine wherein any given combination of gelatines was defective, but to add or subtract the sheets which would just neutralize the objectionable tone of yellow or of blue required an infinity of patience.

The desired result was, however, finally obtained. A spectroscopic examination showed that the successful combinations of gelatine transmitted spectral bands bounded by the following wave-lengths:

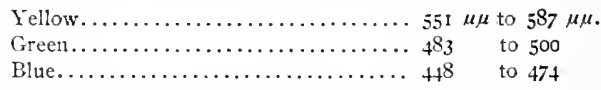

The red stimulus transmitted no part of the visible spectrum.

The equating of the white-values was accomplished by comparing the brightness of the gray sensation aroused by each upon the peripheral retina. A preiminary comparison showed the blue stimulus to have the least white-value of the four. It was therefore determined to reduce the white-value of each of the others to equality with that of the blue. A small motor was attached to the stimulus-lantern, and an episcotister was mounted upon it. Then the two lanterns were detached from the perimeter and fastened, the one close above the other, in a frame. It had been determined previously that the two lanterns emitted light of equal brightness. The combination of gelatines which was to furnish the stable blue stimulus was now placed in the front of the fixation-lantern (the small fixation aperture had been replaced by an aperture $15 \mathrm{~mm}$. in diameter), while one of the other combinations was inserted behind the episcotister in the adjacent stimulus-lantern. A point was fixated by the observer, and the frame containing the two lanterns was moved out from his visual axis until both colors appeared gray. Then the setting of the episcotister was shifted until the two gray lights seemed to possess equal brightness. This experiment was repeated several times, and determinations were made in both an upward and a downward direction to insure accuracy of results; similar determinations were made for the other two stimuli. The average of each set of determinations was taken and recorded for future use.

The color-values were equated by means of a color disc. This disc was made to fit the motor attached to the lantern. Two windows, of exactly the same width, were cut in the disc at points opposite the circular aperture in the front of the lantern. Then the combination of gelatines which gave the stable red was fastened across one of these windows, while the complementary combination which gave the stable green covered the other window. The rotation of the disc before the aperture in the lantern gave a mixture of the red and the green stimuli ; 
and the mixture contained exactly equal proportions of each component, since the two windows were of the same width. The process of equating the color-values of these two stimuli consisted in changing the combinations of gelatines in the windows by adding, subtracting, or substituting until the mixture showed no trace of color. When this result had been attained, when the mixture of the two stimuli in equal proportions gave a colorless gray, their color-values could be said to be equivalent.

The processes of equating the color-values and the white-values were, as a matter of fact, carried on simultaneously and not successively, as we have described them. For it is evident that if one equalization had been completed before the other was undertaken, then any considerable change in the composition of either stimulus during the second process of equating would destroy the equation already obtained. The possibility of ever accomplishing the equalizations is realized only by the presence of a great variety of color tones, and of saturations in the gelatines to which one has access.

\section{B. METHOD.}

The method employed in these experiments was analogous to that already described. The observer's retina was adapted to darkness for fifteen minutes before each sitting began. The series opened with the stimulus-lantern at or near the outer end of the quadrant. It was moved in, ten degrees at a time, until the color of the stimulus was perceived. At the next sitting the innermost point at which gray had been reported was the starting point for the more accurate determination of the color limits. The amount of shifting of the lantern after each exposure was now one degree. The series was continued until color was perceived; and the point at which it was first recognized was recorded as the outermost limit of sensitivity to the stimulus in question.

\section{Results.}

Eight half-meridians of the retina were explored in the manner shown in the preceding paragraph. The results show that the zone of stable red is co-extensive with that of stable green; that the zone of stable yellow is co-extensive with that of stable blue; that the yellowblue zone is much more widely extended in all directions that is the redgreen zone; that the nasal side of the retina has the widest extension of color sensitivity, and that there is a wide individual variation in zonal extension. 
The following table shows the numerical results in detail:

Outermost limits of the four color zones.*

\begin{tabular}{|c|c|c|c|c|c|c|c|c|c|c|}
\hline \multirow{2}{*}{$\begin{array}{c}\text { Retinal } \\
\text { meridians. }\end{array}$} & \multicolumn{2}{|c|}{ Observer B. } & \multicolumn{2}{|c|}{ Observer G. } & \multicolumn{2}{|c|}{ Observer J. } & \multicolumn{2}{|c|}{ Observer P. } & \multicolumn{2}{|c|}{ Observer S. } \\
\hline & R. & G. & $\mathrm{R}$. & G. & $\mathrm{R}$. & G. & R. & G. & R. & G. \\
\hline Down... & 28 & 27 & $3 \mathrm{I}$ & 32 & 34 & 35 & 23 & 22 & 25 & 25 \\
\hline Down-In.... & 34 & 34 & 38 & 36 & 37 & 40 & 28 & 25 & 25 & 27 \\
\hline In $\ldots \ldots \ldots$ & 47 & 46 & 53 & $5 I$ & 47 & 50 & 43 & $4 \mathrm{I}$ & 36 & $3^{8}$ \\
\hline In-Up........ & 39 & $4 \mathrm{r}$ & 44 & 43 & 43 & 40 & 32 & 28 & 28 & 27 \\
\hline Up $\ldots \ldots \ldots \ldots$ & 39 & 37 & 37 & 38 & 38 & $3^{8}$ & 25 & 26 & 23 & 22 \\
\hline Up-Out ..... & 32 & 33 & 36 & 37 & 36 & 34 & 24 & 25 & 25 & 25 \\
\hline Out......... & 34 & $3^{2}$ & 35 & 34 & 35 & 33 & $3 \mathbf{I}$ & 29 & 29 & 28 \\
\hline Out-Down... & 30 & 30 & $3 I$ & 32 & 28 & 27 & 27 & 25 & 25 & 24 \\
\hline \multirow{2}{*}{$\begin{array}{c}\text { Retinal } \\
\text { meridians. }\end{array}$} & \multicolumn{2}{|c|}{ Observer $\mathbf{B}$. } & \multicolumn{2}{|c|}{ Observer G. } & \multicolumn{2}{|c|}{ Observer J. } & \multicolumn{2}{|c|}{ Observer $P$. } & \multicolumn{2}{|c|}{ Observer S. } \\
\hline & Y. & B. & Y. & B. & Y. & B. & $Y$. & B. & Y. & B. \\
\hline Down. & \multirow{8}{*}{\multicolumn{2}{|c|}{ 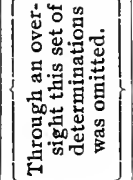 }} & 46 & 43 & 49 & 50 & 37 & 35 & 40 & 43 \\
\hline Down-In. & & & 67 & 70 & 59 & 55 & 46 & 46 & 43 & 45 \\
\hline & & & 73 & 75 & $7 \mathrm{I}$ & 70 & $5^{8}$ & 57 & $5^{6}$ & 53 \\
\hline In-Up. & & & 58 & 56 & 65 & 62 & 40 & 44 & 40 & 39 \\
\hline Up..... & & & 59 & 56 & 52 & 49 & 43 & 40 & 45 & 40 \\
\hline Up-Out & & & 55 & 55 & 47 & 49 & $3^{8}$ & $3^{8}$ & 37 & 39 \\
\hline Out.... & & & 49 & 50 & 48 & 50 & 45 & 48 & 46 & 45 \\
\hline Out-Dowr & & & 44 & 44 & 39 & 42 & 40 & 37 & 40 & 36 \\
\hline
\end{tabular}

* It should perhaps be mentioned that this series of determinations was made toward the close of the investigation. Before these experiments were entered upon, all five observers had had some month' experience with color-stimuli applied to the horizontal meridian of the retina (the out and in meridians of the above table). It is probable that this preliminary training brought about a refinement of color discrimination upon the "out " and "in" meridian, and that the zonal determinations of our table extend beyond the normal limits in tbese two directions. 


\section{DISCUSSION OF RESULTS.}

Our investigation of the changes of color-tone in indirect vision has yielded results which are in harmony with the all but unanimous testimony of previous investigators. The contention of Woinow and Klug that yellow appears green in indirect vision has not been confirmed, nor has Hellpach's discovery upon the periphery of the absence of the sensation of yellow and of the presence of a "gegenfarbige Zone." Our determinations of the relative extension of the retinal zones are in agreement with those of all other investigators who have worked under standardized conditions of experimentation. Moreover, it has been established by the present investigation that the coincidence of the zones of each pair of "stable" colors which was previously found to be valid for the light-adapted retina, holds also for the dark-adapted retina.

The phenomena which we have found to attend upon the continuous stimulation of the peripheral retina, and those which have been shown to persist as an after-effect, upon the removal of the stimulus, are, we believe, for the most part, here pointed out for the first time, although they have, in part, been vaguely foreshadowed in the literature ever since the days of Troxler, Purkinje, and Aubert. So far as we have been able to discover, however, they have never been investigated in satisfactory detail. And the present paper can not hope to do more than to call attention to their existence, and emphasize the necessity of a more detailed investigation of their characteristics.

As to our observation of the rapid fading of color from peripheral images, it is interesting to note that the same phenomenon was described by Troxler, just one hundred years ago. (See pp. $7 \mathrm{f}$.) The existence of successive phases in this process of chromatic adaptation is suggested in the investigation of Landolt and Charpentier* and is discussed in the more recent work of McDougall. $\dagger$ That the phenomena of direct and of indirect vision are, at least to some extent, analogous in this regard, is clear from the familiar observation that the color may wholly disappear from the central image with continued fixation.

The difficulty which we encountered in the production of afterimages upon the peripheral retina was also experienced by Foerster,

*Landolt et Charpentier. Des sensations de lumière et de couleur, dans la vision directe et dans Ia vision indirecte, Comptes Rendus, LXXXVI, 1878,
pp. 495 ff.

tW. McDougall. The Sensations Excited by a Single Momentary Stimulation of the Eye, British Journal of Psychology, I, 1904, p. 85 . 1857 , S. 32 . 
by Aubert, ${ }^{1}$ and by Franz. ${ }^{2}$ Indeed, Franz found it impossible under the conditions of his experiments to arouse an after-image at a greater degree of eccentricity than $30^{\circ}$, and Foerster obtained but a very indistinct after-image when the peripheral retina $\left(45^{\circ}\right.$ from the visual axis) was stimulated by a ray of direct sunlight.

It seems, too, that the persistent after-effects which made themselves felt in our experiments upon the peripheral retina are analogous in character with the after-images of direct vision. Attempts have been made by Exner, ${ }^{3}$ Hess, ${ }^{4}$ Basevi ${ }^{5}$ and others to determine how the retinal function is modified by local chromatic adaptation. ${ }^{6}$ These investigations, which were for the most part confined to direct vision, establish the law that fatigue by any color stimulus increases the retinal sensitivity to the complementary color, and that on subsequent stimulation a sensation of the complementary color tends to arise. Our statement regarding the latent or subliminal character of these after-effects finds confirmation in a demonstration which has recently been described by McDougall. ${ }^{2}$ This investigator finds that when the central afterimage has run its course and finally disappeared from view, it still exists in latent form, from which it may be revived by a restimulation of the retina. An analogous phenomenon was long since pointed out by Hering. ${ }^{\mathrm{A}}$

It must, however, be mentioned that if we accept the testimony of Aubert and of Franz as to the color of the peripheral after-image, our analogy breaks down. For both these investigators report that the peripheral after-image is of the same color as the central-that, $\epsilon . g$., the after-image of a purple stimulus is green, no matter at what part of the retina the after-image be aroused. That this statement is erroneous, we have succeeded in demonstrating by means of an experiment in which an intensive purple stimulus and a long exposure were employed. We found that the application of this stimulus to different regions of the retina gave the following after-images: Green at $0^{\circ}$, blue-green at $25^{\circ}$,

${ }^{1} \mathrm{H}$. Aubert. Ueber das Verhalten der Nachbilder auf den peripherischen Theilen ider Nethaut. Moleschott's Untersuchungen, IV, 1858, S. 220ff.

2 S. I. Franz. After Images, Psychol. Review, Mon, Supp. III, 1899, p. 29.

$3 \mathrm{~S}$. Exner. Ueber die Functionsweise der Netzhantperipherie und den Sitz der Nachbilder, Graefe's Archiv., XXXII, 1, 1886, S. $233 f f$.

$\$$ C. Hess. Ueber die Tonänderung der Spectralfarben durch Ermüdung der Netzliaut mit homogenem Lichte., Graefe's Archiv., XXXVI, I, I890, S. I2ff.

5 V.Basevi. Influenza dell'adattamento sulla sensibilità retinica per la luce e per i colori., Annali d'Ottolmologia, XVIII, 189o, p. 480.

${ }_{6}$ The work of Schön, Charpentier, and Peschel need not be discussed in this conreotion, since their results are expressed in terms of the influence of chromatic adaptation upon the "light sense." Treitel and Landolt deal solely with the effects of general achromatic adaptation.

? IV. McDougall. Some New Observations in Support of Thomas Young's Theory, etc., Mind, N. S., X, r9or, p. 55 .

${ }^{8}$ E. Hering. Zur Lehre vom Lichtsinne, Wien, 1878 , S. $129 f$. 
bluish at $40^{\circ}$, and dark gray (?) at $50^{\circ}$. The results of this experiment are fully in accord with the findings of Adamük and Woinow,* who also report that the color of the after-images aroused at any retinal region is complementary to the color of the primary sensation produced at that region. Our results are further confirmed by the data contained in a more recent paper by Walther. $\dagger$

All of this goes to show that the phenomena which we have described in the foregoing pages as being characteristic of indirect vision are similar in kind throughout to the phenomena of direct vision. The whole retinal surface, with the exception of the macula and the blindspot, is endowed with a similar function, to the extent, at least, that no region possesses a capacity which is wholly lacking in any other region. The color sensitivity of the periphery is unquestionably less acute than that of more central areas, and in consequence of this diminished sensitivity a constant stimulus may arouse different sensations at different regions. It can not, however, be said that any part of the normal retina, save the macula and the blind-spot, is wholly or even partially colorblind. For the whole manifold of sensation qualities which any region is capable of furnishing may, under appropriate conditions of stimulation, be furnished by every other region.

Hellpach's discovery that a yellow stimulus gives no sensation of yellow in indirect vision has not been confirmed by our results. Our experience with the stimulus which he has called yellow in his paper convinces us that Hellpach and the present writer differ in their employment of color names. But it is difficult to understand how this difference of terminology can account for his " discovery." For one can not comprehend how any part of the spectrum can, under normal conditions, appear more orange upon peripheral than upon paracentral regions of the retina. And even the most distinctly orange stimulus must appear yellow before it can pass over into gray in its progressive recession from the visual axis. $\neq$

\footnotetext{
*Adamük and Woinow. Beiträge zur Theorie der negativen Nachbilder, Graefe's Archiv., XVII, I, I871, S. I4If.

tAnthon Walther. Beobachtungen über den Verlauf centraler und extramacularer Nachbilder, Pflüger's Archiv., IxXVVII, I and 2, I899, S. 53-69.

$\$$ The recent testimony of Peters upon this point leaves no room for doubt as to what are the facts of the case. Peters, who, it may be mentioned, worked in the same laboratory as Hellpach, employed an exact duplicate of Hellpach's yellow stimulus, and obtained results which support our findings as against Hellpach's. Peters found that the stimulus in question (which Hellpach had described as being composed of monochromatic light from the sodium line) was frequently identified as yellow-orange in direct vision. He reports further that it invariably appeared yellow upon the peripheral retina before passing over into gray. That is, it invariably appeared yellow when its lnminosity was so weak as to produce any marked change of tone in indirect vision. (W. Peters. Die Farbenempfindung der Netzhautperipherie, u. s. w., Archiv für die Gesamte Psyohologie, III, 1904, S. $374 \mathrm{f}$ )
} 
Hellpach's "gegcnfarbige Zone" is doubtless a product of the latent after-effects of stimulation (retinal fatigue), which we have described (pp. 57 ff.). It will be remembered that in determining the position of the zonal limits, he moved his stimulus in from the periphery, each exposure being made at a point ten degrees nearer the visual axis than its predecessor. This procedure was continued until color was perceived; but since the steps had been too long to guarantee an accurate determination of the limits of the color-zone, he went back 20 degrees from the point at which color was first reported and readvanced over the same ground with shorter steps. Of course, this method provided the most favorable conditions possible for the operation of the residual after-effects of stimulation. For his final determinations were invariably made upon a region which he had previously fatigued. It was inevitable that this method should yield the abnormal results which he reports. And if he had followed the same procedure in his exploration of the other regions of the retina, he would doubtless have found that the whole retinal surface, save the fovea and the blind-spot alone, is one vast "gegenfarbige Zone." On the other hand, our own results justify the prediction that if he had given the retina an adequate rest before each stimulation, he would have found no trace of a "gegenfarbige Zone" at any part of the retina. 


\section{INTERPRETATION OF RESULTS,}

How are out results to be explained? Can they be brought into line with any or all of the theories of color-vision now in the field? Can they contribute to an evaluation of the relative merits of the rival theories?

Any attempt to express our results in terms of physiological process reveals the possibility of four general principles of interpretation: (I) It may be held that the phenomena which have been found to be claracteristic of indirect vision are wholly due to the peculiar objective conditions which must, from the nature of the case, attend the stimulation of the peripheral retina. (2) On the other hand, it may be held that these phenomena are the result of a peculiarity of structure or of chemical composition of the peripheral retina. (3) It may be conceived that the phenomena in question are to be referred to a simultaneous cooperation of the factors mentioned under $\mathbf{I}$ and 2. And (4) all of these views may be discarded as inadequate; one may conclude, instead, that the phenomena in question can not be explained in terms of a modification of retinal process at all, and conceive that they are to be referred to a cerebral or other central process whose nature it is impossible to envisage or describe.

(I) The first view either conceives the retinal surface to be uniform in structure and composition throughout its whole area, or regards those differences which may be held to occur as being of negligible significance. It refers the transitions of color-tone to the physical form of the visual organ, and the spatial arrangement of its parts, emphasizing the fact that the retinal surface occupies such a position relative to that of the pupil and of the lens, that its outlying parts possess less favorable conditions for vision than its central region. The advocate of this view need not assume that the color-sensing substance with which the periphery is supplied is in any wise different from that which is found at the center. For the defective refraction of oblique rays of light, and the non-perpendicular position of the plane of the pupil to that of the path of the incident light naturally and necessarily give rise to a less bright and less well-defined peripheral image. In short, a given pencil of rays constitutes a lesser physiological stimulus in indirect than in direct vision, for the simple reason that in the former a part of the light fails to gain access to the pupil, while the part which does enter is imperfectly focused upon the retma.

This view as here formulated has perhaps never been advocated by any single writer; but it is a composite statement of the positions held by Albini on the one hand, and on the other by a group of investigators 
composed of Raehlmann, Landolt, Lamansky, and possibly Aubert. There can be no doubt that the peripheral image is relatively faintly illuminated, and it may be granted that it is also characterized by ill definition. But one finds it difficult to see how these differences in objective conditions of stimulation can account for all of the phenomena of indirect vision. For if the phenomena in question are a product of the lesser luminosity of the peripheral image, one would expect to find a thoroughgoing parallelism between the changes of tone which occur when an image moves across the retina and those which occur when an image occupying a constant retinal position is varied in brightness. That the analogy between these two series of changes is anything but perfect has frequently been demonstrated. Nor can the problematic influence of defective refraction save the theory. For Albini himself has shown that the progressive correction of refraction in indirect vision does not run parallel with the different refrangibility of the colored lights employed. Indeed it seems probable that increased brightness of image was the determining factor in extending Albini's color-zones, and that refractive correction had nothing to do with the matter. Moreover, the fact that the keenness of the peripheral "light sense" is undiminished, or even increased, would seem to indicate that the imperfect optical properties of the visual organ have been over-emphasized.

(2) The second view conceives the histological structure or chemical constitution of the peripheral retina to be different from that which obtains at the center, and brings this structural or chemical differentiation into relation with the difference between the functions which have been established in the two cases. The elaboration of this conception has taken different forms in the hands of different theorists.

(a) Maxwell believed that the absorption which results from the pigmentation of the yellow-spot is sufficient to account for the transitons of color-tone which he observed. Maxwell's principle is, of course, powerless to account for changes in tone which occur beyond the limits of the macula.

(b) Helmholtz conceived that of the three visual substances but two are distributed over the whole retinal surface. The red-sensing substance is absent from the periphery, which is therefore red-blind. This conception was supported and extended in different directions by certain of his disciples. But the later Helmholtzians-and subsequently Helmholtz himself-concede its inadequacy.

(c) Closely allied with the earlier Helmholtzian view is the theory which posits an integrity of structure of the whole retinal surface, but assumes that an impairment of function has taken place in the sensitive 
substance of the periphery. This view is advocated by Schön and by Fick and is ultimately adopted by Helmholtz as representing his final position. We have elsewhere (pp. 39f.) shown cause for refusing to accept it.

(d) According to the theory of Mrs. Ladd-Franklin, the visual substance is to be conceived as a product of a progressive development, in which three stages may be differentiated. In its primitive form the photo-chemical substance is decomposable by light of all sorts-the conscious product of the decomposition being an achromatic sensation. In this form the substance occurs only in the rods, and this supposition coincides with the fact that the extreme periphery of the retina contains rods almost exclusively. In its second stage of development, where it occurs only in the cones, the visual substance is differently decomposable by long-waved and by short-waved light. Here arise the sensations of yellow and of blue, besides the achromatic series. This is the stage of development which is represented by the "dichromatic" color $z$ zone of the normal retina, $i$. $e$, the zone in which, with moderate conditions of stimulation, blue and yellow are the only colors perceived. In its completely developed form the yellow-producing substance has reached a still higher stage of development and is now capable of being separately decomposed by erythrogenic (red-producing) and chlorogenic (green-producing) rays of light. This form of the photochemical substance occurs in considerable quantity only in the central and paracentral regions of the retina (hence called by Mrs. LaddFranklin, the "tetrachromatic zone"). The normal retina thus contains visual substance in all three stages of development ; and the proportion of the less highly developed substances increases with increase of distance from the center.

This theory has the advantage of being cast in an evolutionary mold, and of accounting for the relative subjective imperfection of the peripheral retina in evolutionary terms. It connects this imperfection with the relatively undeveloped structure which is known to be characteristic of the periphery, and with the fact, established by Ramon $y$ Cajal, that the rods are undeveloped cones.

The hypotheses of this theory readily fall into line with all of the facts revealed by the present investigation. The differently decomposable substances are so distributed as to render it plausible that the retina should contain three concentric zones, and that these zones should vary in extent with variable conditions of stimulation. The retinal process which underlies the fading of peripherally seen colors through yellow or blue to gray, is rendered easy of envisagement by the hypothesis 
that the photo-chemical substrates of the three visual processes represent different degrees of complexity of development, and hence presumably also represent different degrees of tenacity of function. The rapid adaptation and the persistent after-effects of the peripheral retina may be traced to an ad hoc hypothesis of a peculiar degree of chemical stability of partially dissociated molecular groups. The seeming contradiction between the presence of a bluish tinge in the stable red and the stable green and the absence of that tinge from the specific sensations furnished by the erythrogenic and chlorogenic substances, disappears when we remember the influence of the yellow pigmentation of the macula.*

(e) The Hering theory assumes the existence of three sorts of visual substance, each of which has its own retinal distribution, and its own specific function. The whole retinal surface is supplied with all three substances, but their distribution is such that any given region contains a richest supply of white-black substance, and a scantest amount of red-green substance. These hypotheses adapt themselves to the coincidence of the zonal limits of the pairs of colors, because the substance which is active in the sensing of a color is also supposed to mediate the sensation of its complementary. The lesser extension of the red-green zone is referred to the relatively circumscribed distribution of the red-green substance. In common with all other theories it must trace the variability of zonal extension to the fact that the variation of a stimulus of constant tone, produces a variation of intensity of physiological action. The fading out of the peripheral colors through yellow or blue to gray is accounted for by the assumption that the retina contains a richer supply of white-black substance than of yellow-blue, and of yellow-blue than of red-green. The relatively rapid adaptation of the peripheral retina is referred to its relatively scant supply of chromatic substance-a hypothesis which also accounts for the lesser saturation of colors seen in indirect vision. The persistent duration of the after-effects of peripheral stimulation is expressed physiologically in the statement that the restoration of chromatic equilibrium is more sluggish upon peripheral than upon central regions. Whether this physiological characteristic can be brought into relation with the relatively undeveloped state of the peripheral retina is not clear.

(3) The third view occupies a mediating position between the first and the second. It has never attracted a following in the literature, nor

*Mrs. C. Ladd-Franklin. Eine neue Theorie der Lichtempfindung. Zeitschrift für Psychologie und Physiologie der Sinnesorgane, IV, I893, S. 2 II-24r; On Theories of Light Sensation, Mind, N. S., II, 1894, pp. 473-489; Baldwin's Dictionary of Philosophy and Psychology, II, 1902, pp. $792 \mathrm{ff}$. 
can a strong case be made out in its behalf. For while it is doubtless true that the periphery possesses less favorable optical conditions, still one can not understand how these can furnish even a partial explanation of the visual phenomena which are here to be accounted for.

(4) The fourth conception is wholly different from any of the others. It represents an attitude of despair, in that its advocate confesses his failure to bring his facts into relation with any retinal process which can be conceived in analogy with the phenomena or principles of physics, of physiology, or of chemistry; and feels himself obliged to invoke the aid of a mysterious cerebral or other central process whose nature he also fails to characterize. Such a view as this might win the temporary adherence of the scientist who temporarily despairs of finding a more definite or more promising envisagement of the process of color vision; but it can scarcely hope to be accepted excepting as a temporary resting-place, or as a last resort to be chosen when all others fail. Such a view has been suggested by Landolt and Charpentier, and is mentioned as a tentative hypothesis by von Kries. It is too vague and ethereal to offer a promising field for discussion. 


\section{SUMMARY.}

The essential features of our results may be summarized as follows :

(I) In moving across the retina, the images of colored objects of moderate size and luminosity pass through certain regular series of transitional tones. On the basis of these changes of color-tone we may conceive the retinal surface to contain three concentric zones-an extreme peripheral zone upon which all stinuuli of moderate area and luminosity appear colorless; an intermediate zone where they appear yellow or blue (two exceptions will be mentioned later), and a central zone where red and green appear.

(2) The position and extent of the color zones are not fixed, but variable. Their area in any given case depends upon the momentary condition of retinal adaptation, and upon the brightness and saturation of the stimuli employed. (Other investigators have established the fact that zonal extension is also a function of the character of the background, the condition of optic refraction, and the magnitude of visual angle of stimulus.) Hence the absolute and relative extension of the zones may be varied at will. It is possible, for example, to choose a violet stimulus which can be recognized as violet at the extreme periphery, and it is equally possible to choose another stimulus of the same tone of violet which can not be recognized as violet at the center of the fovea.

(3) Of all possible colors, there are four and only four which undergo no change of tone in indirect vision. These are a purplishred (non-spectral), a yellow (about $570 \mu \mu$ ), a bluish-green (about $490 \mu \mu$ ), and a blue (about $460 \mu \mu$ ).*

(4) When stimuli representing these four stable colors are equated in white-value and in color-value, the retinal zone upon which the red is recognized coincides with that of the green, and the zone of the yellow coincides with that of the blue. The extension of the yellowblue zone is considerably wider than that of the red-green zone.

(5) When a color stimulus is applied to an eccentric region of the retina, the color rapidly fades out of the image. The fading process follows a gradual course, and passes through a regular series of transitions. Here, too, the order of change is through yellow (for stimuli of long-waved tones) or blue (for stimuli of short-waved tones) to gray. If the stimulation be sufficiently intensive or sufficiently long-continued,

\footnotetext{
*These numbers represent the wave-lengths at the center of the spectral bands transmitted by our stimuli. A more accurate description of the composition of the stimuli will be found on p. 60 .
} 
the complementary blue or yellow appears as a final stage. All of these changes occur in the presence of the stimulus.

(6) The stimulation of the peripheral retina is attended by characteristic after-effects. These may be described as being rudimentary after-images. They are analogons with after-images in that $(a)$ they possess a complementary character; but they differ from after-images in that $(b)$ they are (or at least were under our experimental conditions) wholly latent and unconscious (or sub-liminal). Their presence was felt, however, in the changed quality of the sensation aroused by subsequent stimulation. (c) A prominent characteristic of these aftereffects is their persistent duration. They can be got rid of only by resting the eye for a considerable period after each stimulation. (d) As to their spatial attributes, our experiments justify only the general statement that they seem to extend over a wider retinal area than did the images which occasioned them.

(7) There seems to be no doubt that Hellpach's zone of complementariness is an artifact, and that its discovery is wholly due to the experimenter's failure to avoid retinal fatigue in his explorations. The peripheral retina is readily fatigued, and the fatigue-effects here persist with extraordinary tenacity. This characteristic is also present, though in lesser degree, at every other part of the retinal surface. When a color-stimulus which has already fatigued any region of the retina is reapplied to the same or an adjacent region before the retina has fully recovered from its previots stimulation, the resultant sensation tends to appear either colorless or in a tone which is complementary to that of the primary sensation aroused by the same stimulus at that point.* This phenomenon has been abundantly demonstrated in this and in numerous other investigations; it is unquestionably the same phenomenon which Hellpach reports. Hellpach is in error, however, in sup-

*It is, of course, incorrect to say that these fatigue-products are complementary to the "objective Farbc" of the stimulus as seen in direct vision. (See Hellpach, 1. c., S. 537.) Such a characterization is true only in case the stimuli employed represent stable tones. In every case the tone of the "fatigue sensation" aroused at a given region is complementary to the primary or "nonfatigue" sensation aroused at that region. Thus a purple stimulus is attended by green after-effects only at those regions where the purple of the stimulus is recognized. Upon those regions where this stimulus appears yellow, subsequent stimuli seem to be tinged with blue. This is in accord with Hellpach's finding that red, orange, and yellow all appear bluish upon the "gegenfarbige Zone." Strangely enough, he reports that green appeared yellow-reddish and purple appeared yellow-greenish upon this outermost zone. This irregularity can be explained only on the assumption that Hellpach's green and purple stimuli were more intensive than the others. 
posing that this complementary function is a normal characteristic of the non-fatigued retina; he is no less mistaken in supposing that it is peculiar to the periphery alone. The same phenomenon can be made to appear at every part of the retinal surface. It is invariably absent from periphery and center alike, when care is taken to delay the application of the stimulus until the retina has fully recovered from the effects of previous stimulation.

(8) Our results are in accord with the Hering and Franklin theories of color rision. They can not be reconciled with any other theory with which the writer is acquainted.

AgNEY, W. DE W.

\section{BIBLIOGRAPHY.}

The Sensitiveness of the Eye to Light and Colour. Nature, XLVII, 1893, pp. $538-542$.

Colour Vision. New York. (No date.) The Tyndall Lectures delivered at the Royal Institution in 1894 .

The Sensitiveness of the Retina to Light and Colour. Philosophical Transactions, 190A, 1897, pp. 155-195.

The Colour Sensations in Terms of Luminosity. Phil. Trans., 193, 1900, pp. 259-28\%.

ADAMÜK UND WoInOW.

Beiträge zur Lehre von den negativen Nachbildern. Graefe's Archiv. f. Ophthalm., XVII, 1, I871, S. 135-157.

ALB1NI, E.

Della visione indiretta delle forme e dei colori. Giornale d. R. Accademia di Medicina di Torino, XXXIV, i886, pp. 657-675.

Sulla visione indiretta delle forme e dei colori. Annali di Ottalmologia, XV, I887, pp. 482-485.

Aubert, Hermann.

Ueber die Grenzen der Farbenwahrnehmung auf den seitlichen Theilen der Netzhaut. Graefe's Archiv. f. Ophthalm., III, 2, I857, S. 38-68.

Ueber das Verhalten der Nachbilder auf 'den peripherischen Theilen der Netzhaut. Moleschott's Untersuchungen, IV, 1858, S. 215-240.

Ueber die durch den elektrischen Funken erzeugten Nachbilder. Moleschott's Untersuchungen, V, 1859, S. 279-314.

Untersuchungen über die Sinnesthätigkeiten der Netzhaut. Poggendorff's Annalen, CXV, 1862, S. 87-116; CXVI, 1862, S. 249-278.

Physiologie der Netzhaut. Breslau, 1865 .

Grundzïge der physiologischen Optik. Leipzig, 1876.

Basevi, Vitrorio.

Sulla sensibilità della perifenia della retina per la luce e per $\mathrm{i}$ colori in occhi normali ed in alcuni casi patologica. Annali di Ottalmologia, XVIII, 1889 , pp. $4 \mathrm{I}-52$.

Influenza dell'adattamento sulla sensibilità retinica per la luce e per $\mathrm{i}$ colori. Ann. di Ott., XVIII, I890, pp. 475-481.

BeliLARMinow, L.

Ueber intermittirende Netzhautreizung. Graefe's Archiv., XXXV, I, 1889, S. $25-49$.

Bow, R. H.

On the Change of Apparent Color by Obliquity of Vision. Proceedings of the Royal Society of Edinburgh, VII, 1871, pp. 155-160. 
BRIESEWITZ, -

Ueber das Farbenselien bei normalem und atropischem Nervus Opticus, Inaug. Diss., Griefswald, 1872.

BULL, OLE.

Studien über Licht- und Farbensinn. Graefe's Archiv., XXVII, I, I88I, S. 54-154.

Bemerkungen über den Farbensinn unter verschiedenen physiologischen und pathologischen Verhältnissen. Graefe's Archiv., XXIX, 3, I883, S. 71-II6.

Sur la périmètrie au moyen de pigments colorés. Annales d'Oculistique, CX, 1893, pp. 169-181; CXI, I894, pp. 284 .

Perimetrie. Bonn. 1895 .

Burch, Geo. J

On Artificial Temporary Color Blindness, etc. Phil. Trans., 19I8, I899, pp. I-34.

Butz, R.

Vorläufige Mittheilungen über Untersuchungen u. s. w. Archiv. für (Anatomie und) Physiologie, I88I, S. 437-445.

Unterswohungen über die physiologischen Functionen der Peripherie der Netzhaut. Inaug. Diss., Dorpat, I883.

Cattell, J. McKenen.

The Inertia of the Eye and Brain. Brain, VIII, I886, pp. 295-3I3.

Chodin, A.

Zur Lehre von den Farbenempfindungen auf der Periphenie der Netzhaut. Petersburg. Med. Anzeiger, 1875, Nos. I0-I3.

Ueber die Empfindlichkeit für Farben in der Peripherie der Netzhaut. Graefe's Archiv., XXIII, 3, I877, S. I77-208.

Ueber die Abhängigkeit der Farbenempfindung von der Lichtstärke. Sammlung phys. Abhandl, von W. Preyer, 1, 7, 1877, S. I-66.

Charpentier, A.

De la vision avec les diverses parties de la rétine. Archives de physiologie, IX, I877, pp. 894-945.

Sur la duration de l'adaptation de la rétine à l'obscurité. Compt. Rend. de la Société de Biologie, II. I885, pp. 31 off.

Expériences sur la marche de l'adaptation rétinienne. Archives d'Ophthalunologie, VI, I88ó, pp. 294-3oi.

L'inertie rétinienne et la théorie des perceptions visuelles. Archives d'Ophthalm., VI, I886, pp. I I 4 ff.

La lumière et les conleurs. Paris, I8S8, 352pp.

(See also Landolt et Charpentier.)

Dieterici, C. (See König, A., und Dieterici, C.)

DOBRoWOLSKY, W

Ueber die Empfindlichkeit des Auges gegen verschiedene Spectralfarben. Graefe's Archiv., XVIII, I, I872, S. 66-92.

Zur. Kenntnis über die Empfindlichkeit des Auges gegen Farbentöne Graefe's Archiv., XVIII, 1, 1872, S. 98-103.

Ueber die Empfindlichkeit des Auges gegen die Liohtintensität der Farben (Farbensinn), im Centrum und aui der Peripherie der Netzhaut. Pfluger's Archiv., XII, I875, S. 44I-47I.

Ueber den Unterschied in der Farbenempfindung bei Reizung der Netzhaut an einer und an mehreren Stellen zu gleicher Zeit. Pfluger's Archiv., XXXV, 1884, S. $537-54$ I.

Ueber die Empfindlichkeit des normalen Auges gegen Farbentöne auf der Peripherie der Netzhaut. Graefe's Archiv., XXXII, I, 1886, S. 9-32.

Donders, F. C.

Ueber Farbensysteme. Graefe's Archiv., XXVII, I, I88I, S. 155-223.

Noch einmal die Farbensysteme. Graefe's Archiv., XXX, I, I884, S. 15-90.

DrotT, A.

Die Aussengrenzen des Gesichtsfelds für weisse und iarbige Objecte bei normalem Auge. Inaug. Diss., Breslau, I894, pp. 32. 


\section{COLOR SENSITIVITY OF THE PERIPHERAL RETINA.}

ERdmann, O. E.

Ueber ungleiche Ermüdung centraler und peripherischer Theile der NetzEXNER, S haut. Centralblatt für prakt. Augenheilkunde, I884, S. I20ff.

Die Empfindungszonen des Sehnervenapparates. Pflüger's Archiv., XI, I 875 , S. 581-602.

Weitere Untersuchungen über die Regeneration in der Netzhatst und über Druckblir dheit. Pflüger's Archiv., XX, 1879, S. 614-626.

Ueber die Funktionsweise der Netzhautperipherie und den Sitz der Nachbilder. Graefe's Archiv., XXXII, I, I886, S. 233-252.

Fick, A.

Die Bilder seitlich gelegener Objekte. Hermann's Handbuch der Physiologie, III, I, I879, S. 76-82.

Zur Theorie des Farbensinns bei indirektem Sehen. Pflüger's Archiv., XLVII, I890, S. $27+-285$.

FICK, A. E.

Ueber Erholung der Netzhaut. Sitzungsbericht der phys. med. Gesellschait zu Würzburg. No. 9, I\$go.

Studien über Licht- und Farbenempfindung. Pflüger's Archiv., XLIII, I888, S. $4 \mathrm{I}$.

FICK, A. E., UND Gürber, A.

Ueber Netzhauterholung. Bericht der Ophthalm. Gesellschaft in Heidelberg, II, I\$99, S. 54ff, and Graefe's Archiv., XXXVI, 2, I89o, S. 245-30r.

FOERSTER.

Ueber Hemeralopie und die Anwendung eines Photometers im Gebiete der Ophthalmologie. Habilitationsschrift, Hamburg, 1857, S. 32.

GüRBER, A. (See Fick und Gürber.)

GUILLERY.

Vergleichende Untersuchungen über Raum- Licht- und Farbensinn in Zentrum und Peripherie der Netzhaut. Zeitschrift für Psychologie und Psysiologie der Sinnesorgane, XII, I\&g6, S. 243-313.

HARRIS, D. F.

A Case of Vivid After-Images Explained on Hering's Theory. Brain, XXIII, I900, pp. 69I-693.

HARTSHORN, H.

On Some Disputed Points in Physiological Optics. Proceedings of the American Philosophical Society, XVI, 1876, pp. 218ff.

HegG, E.

Zur Farbenperimetrie. Graefe's Archiv. XXXVIII, 3, I892, S. I45-I68.

La périmètrie des cotleurs. Annales d'Ocultistique, CIX, I893. pp. 32I-347.

Sur la périmètrie au moyen de pigments colorés. Ann. d'Ocul., CXI, I894, Pp. I22-I 27.

HELLPACH, WV.

Die Farbenempfindung in indirectem Sehen. Philosophische Studien, XV, I900, S. 524-554.

HelMhOLTZ, H. roN.

Handbuch der Physiologischen Optik., Leipzig, i856-1866, S. 300-301 and S. 845. Second edition, I885-96, S. 372-375.

HERING, E.

Zur Lehre vom Lichtsinne. Wien, I874 ( $1872-4)$. Second edition, I878.

Ueber die Hypothesen zur Erklärung der peripheren Farbenblindheit. Graefe's Archiv., XXXV, 4. 1889, S. 63-85.

Prefatory note to Hillebrand's paper on specific brightness, $q . v$.

Berichtigung zur Abhandlung über periphere Farbenblindheit. Graefe's Arehiv., XXXVI, I, I890, S. 264.

Prüfung der sogenannten Farbendreiecke mit Hülfe des Farbensinnes excentrischer Netzhautstellen. Pflüger's Archiv., XLVII, I890, S. 4I7-438.

Ueber den Einfluss der IIacula lutea auf spectrale Farbengleichungen. Pflüger's Archiv., LIV, I893, S. 277-312. 
HESS, C.

Ueber den Farbensinn bei indirectem Sehen. Graefe's Archiv., XXXV, 4, I889, S. I-62.

Ueber die Touänderungen der Spectralfarben durch Ermüdung der Netzhaut mit homogenem Lichte. Graefe's Archiv., XXXVI, I, I890, S. I-32.

Untersuohungen über die nach kurzdauernder Reizung des Sehorgans auftretenden Nachbilder. Pflüger's Archiv., XLIX, I891, S. I90-208.

Ueber die Unvereinbarkeit gewisser Ermüdungserscheinungen des Sehorgans mit der Dreifasertheorie. Graefe's Archiv., XXXIX, I893, S. 45-70.

Studien über Nachbilder. Graefe's Archiv., XL, 2, I894. S. 259-279.

Ueber den Ablauf des Ërregungsvorganges nach kurzdauernder Reizung des Sehorgans bein Normalen und bei total Farbenblinden. Graefe's Archiv., LI, I900, S. 225-256.

HillemRAND, F.

Ueber die specifische Helligkeit der Farben. Sitzungsber. d. $k$. Acad. in Wien, XCVIII, 3, 1889, S. 70-120.

HOCHECKER, TH.

Ueber angeborene Farbenblindheit. Graefe's Archiv., XIX, 3. 1873, S. 1-37. HOLDEN, W. A.

The Testing of the Light Sense in the Periphery of the Retina. Arch. of Ophth., XXIII, I894, pp. 40-49.

HOLMGREN, F.

Die Earbenblindheit u. s. w . Leipzig, 1878,

Studien über die elementaren Farbenempfindungen. Skand. Archiv. f. Physiologie, III, I89I, S. 253-295.

HUECK, A.

Von den Grenzen des Sehenvermögens. Müller's Archiv. f. Anat. Physiol. u. wiss. Med., I840, S. 83-98.

JENNINGS, J. E.

Color Vision and Color Blindness. Philadelphia, 1896.

KirschmanN, A.

Ueber die Helligkeitsempfindung in indirectem Sehen. Philos. Studien, V, 1900, S. 447-497.

Die Farbenempfindung in indirectem Sehen. Philos. Studien, VIII, I893, S. 592-61.4.

The Function of Indirect Vision. Transactions of the Canadian Institute (Toronto), V, 1898, pp. 305-310.

$\mathrm{K}_{\mathrm{LUG}}, \mathrm{F}$. Ueber Farbenempfindung bei indirectem Sehen. Graefe's Archiv., XXI, I, 1875, S. 251-294.

KOLBE, B,

Zur Analyse 'der Pigmentfarben. Graefe's Archiv., XXX, 2, I884, S. I-68.

KöniG, A., und DIETERICI.

Die Grundempfindungen in normalen und anomalen Farbensysteme u. s. w. Zeitschrift f. Psychol. u. Physiol. d. Sinnesorgane, IV, I892, S. 24I-3+7.

KönIG, A. A review of papers by Hering, Hess, and Fick. Zeitschrift f. Psychol. 11. Physiol. d. Sinnesorgane, III, 1\&g2, S. 211-2I3.

VON KRIES, J.

Die Gesichtsempfindungen und ihre Analyse. Leipzig, 1882.

Zur Theorie der Gesichtsempfindungen. Du Bois-Reymond's Archiv. f. Physiologie, I887, S. I I3-II9.

Entgegnung an Herrn E. Hering. PAüger's Archiv., XLI, I887, S. 389-397.

Ueber den Einfluss der Adaptation auf Licht- und Farbenempfindung und über die Function der Stäbchen. Bericht der naturforsch. Gesell. zu Freiburg, IX, I894, S. 6I-7o.

Ueber die functionellen Verschiedenheiten des Netzhautcentrums und der Nachbarteile. Graefe's Archiv., XLII, 3, 1896, S. 95-133.

Ueber die Farbenblindheit der Netzhatperipherie. Zeitschrift f. Psychol. u. Physiol. d. Sinnesorgane, XV, I897, S. $247-279$.

Die Gesiohtsempfindungen. In Nagel's Handbuch der Physiologie des Menschen, Braunschweig, 1904, III, I. 
KRÜKow.

Sur la sensation des couleurs objectives à la périphérie de la rétine. Inaug. Diss., Moscow, 1873 .

Objective Farbenempfindung auf den peripherischen Theilen der Netzhaut. KRIENES, H.

Graefe's Archiv., XX, I, I874, S. 255-296.

The Light Sense and Color Sense in Diseases of the Retina, Choroid and Optic Nerve. Arch. of Ophthal., XXVIII, I899, pp. 416-427.

KUNKEL, A. J.

Ueber die Abhängigkeit der Farbenempfindung von der Zeit. Pflüger's Archiv, IX, I874, S. 197.

Ueber die Erregung der Netzhaut. Pflüger's Archiv., XV, I877, S. 27.

LADD-FRANKLIN, C.

On Theories of Light Sensation. Mind, N. S., II, I893, pp. 473-489.

Eine neue Theorie der Lichtempfindungen. Zeitschrift f. Psychol. u. Physiol. d. Sinnesorgane, IV, 1893, S. 2 II-22I.

Vision. In Baldwin's Dictionary of Philosophy and Psychology. New York and London, 1902, II, pp. 765-799.

LAMANSKY, S.

Ueber die Grenzen der Empfindlichkeit des Auges für Spectralfarben. Graefe's Archiv., XVII, I, I871, S. 123-134, and Poggendorff's Annalen d. Physik u. Chemie, CCXIX, I871, S. 633-643.

LANDOLT, E.

Il perimetro e la sua applicazione. Annali di Ottalmologia, II, I872, pp. $465-484$.

Farbenperception der Netzhautperipherie. Zehender's Klin. Monatsblätter f. Augenheilkunde, XI, 1873, S. 376-377.

De la perception des couleurs à la périphérie de la rétine. Annales d'Oculistique, LXXI, I874, pp. 44-46.

LANDol,t, E., ET Charpentier, A.

Des sensations de lumière et de couleur dans la vision directe et dans la vision indirecte. Compt. Rend., LXXXVI, 1878, pp. 495-497.

LÉPINAY, J. MACÉ DE, ET NICATI, W.

Contribution a l'étude du champ visuel des couleurs. Arch. d'Ophthalm., I, I88I, pp. $437 \mathrm{ff}$. and $506 \mathrm{ff}$.

LEROY, C. J. A.

Champ optique, champ visuel, absolu et relatif de l'oeil. Compt. Rend.,

LIÉVIN, H. CXVI, 1893 , pp. $377-379$.

Ueber die Grösse und Begrenzung des normalen Gesichtsfeldes. Inaug. Diss., Königsberg, I877.

Lough, J. E.

A new Perimeter. Psychological Review, III, I896, pp. 282-285.

LUCKEY, G. IV. A.

Comparative Observations on the Indirect Color Range of Children, Adults, and Adults Trained in Color. American Journal of Psychology, VI, MACH, E. I895, pp. $489-504$.

Ueber die Wirkung der ränmlichen Vertheilung des Lichtreizes auf die Netzhaut. Wiener Berichte, I80́5-8, LII, S. 308-322; LIV, S. I3i-134, and $393-408$; LVII, S. II-19.

MAXWeil, J. CleRk.

On Colour Vision at Different Points of the Retina, Engineer, XXX, 1870, pp. $208 \mathrm{fff}$; Report of the British Association for the Advancement of Science, $187 i$, Notices and Abstracts, pp. $40 f$. 
McDougali, W.

Some New Observations in Support of Thomas Young's Theory of Light and Color Vision. Mind, N. S., X, I90 I, pp. 52-97, 210-245, 347-382.

The Sensations Excited by a Single Momentary Stimulation of the Eye. British Journal of Psyolology, I, I904, pp. 78-II4.

Meisling, A.

Mensuration du champ visuel au moyen d'abjects offerts sous un petit

MösER, C. angle visuel. Thèse. Copenhagen, I899.

Das Perimeter und seine Anwendung. Inaug. Diss., Breslau, I869.

MÜLLER, JoH ANNES.

Zur vergleichenden Physiologie des Gesichtssimes. Coblenz, I8z6.

PABST, A.

Ueber die Bestimmung der Helligkeit farbiger Papiere durch intermittierende Netzhautreizung. Inaug. Diss., Würzburg, I 896.

Parinaud, $\mathrm{H}$.

Influence inégale de l'adaptation rétinienne sur les lumières de réfrangibilité différente; la sensibilité dans la nuacula et les parties periphériques; rôle du pourpre visıel. Bull. et mém. de la société francaise d'ophtahalm., III, 1885, pp. $329 \mathrm{ff}$.

La sensibilité de l'oeil aux couleurs spectrals, etc. Annales d'Oculistique, CXI, I894, pp. 228-256.

La vision. Patis, 1898 .

Peschei, M,

Experimentelle Untersuchungen über die Adaptation der Netzhaut für Peters, W. Farben. Pflüger's Archiv., XXI, I880, S. 405-430.

Die Farbenempfindung der Netzhautperipherie bei Dunkeladaptation und konstanter subjectiver Helligkeit. Archiv. f. d. Gesamte Psychologie,

PIPER, III, I904, S. 354-387.

Ueber Dunkeladaptation. Zeitschrift f. Psychol, u. Physiol. d. Sinnesorgane, XXXI, 1903, S. 161-215.

Purkin Je, J. E.

Beobachtungen und Versuche zur Physiologie der Sinne. I. Beiträge zur Kenntris des Sehens in subjectiver Hinsicht, Prag., I823. II. Neue Beiträge zur Kenntnis des Sehens, Berlin, I825.

RAEHLMANN, E.

Ueber Farbenempfindung in den peripherischen Netzhautpartien u. 6. w. Inaug. Diss., Halle, 1872.

Ueber Verhältnisse der Farbenempfindung bei indirectem und directem Sehen. Graefe's Archiv., XX, I, 1874, S. 15-32.

Ueber Schwellenwerte der verschiedenen Spectralfarben an verschiedenen Stellen der Netzhaut. Graefe's Archiv., XX, I, IS74, S. 232-254.

Ueber Relativen und Absoluten Mangel ides Farbensehens. Berlin, 1900.

REICH, M.

Material zur Bestimmung der Grenzen des Gesichtsfelds u. s. w. Inaug. Diss., St. Petersburg, 1872.

RIVERS, W. H. R.

Vision. In Schäfer's Text-book of Physiology, II, I900, pp. I026-1148.

RUPP.

Ueber die Dauer der Nachempfindung an den seitlichen Theilen der Netzhaut. Inaug. Diss., Königsberg, 1S69.

Schadow, G.

Die Lichtempfundlichkeit der peripheren Netzhauttheile im Verhältnisse zu deren Raum- und Farbensinn. Pflïger's Archiv., XIX, 1879, S. 439-46r.

SCHELSKE, R.

Zur Frarbenempfindung. Graefe's Archiv., IX, 3, I863, S. 39-62. 
SCHIRMER, R.

Ueber erworbene und angeborene Anomalien des Farbensinns. Graefe's Archiv., XIX, 2, 1873 , S. I94-235.

SснӧN, W.

Ueber die Grenzen der Farbenempfindung in pathologischen Fällen. Zehender's Klinisohe Monatsblätter f. Augenheilkunde, 1873, S. 17I-227.

Die Lehre vom Gesichtsfelde und seine Anomalien. Berlin, I874.

Einfluss der Ermüdung auf die Farbenempfindung. Graefe's Archiv., XX 2, 1874, S. $273-284$.

SULZER, MI.

De la périmètrie des couleurs. XI Congrès internat. d'Ophthalm., Utrecht, 1899. pp. 347ff.

SzokAlsky, V.

Ueber die Empfindung der Farben in physiologischer und pathologischer Hinsicht. Giessen, $18+2$.

TREITEL, Th.

Prüfung des Gesichtsfeldes mit Pigmentfarben. Inaug. Diss., Königsberg, 1875 .

Ueber den Werth der Gesichtsfeldsmessung mit Pigmenten für die Auffassung der Krankheiten des nervosen Apparats. Graefe's Archiv., XXV, I879, 2, S. 29-I30; 3. S. 1-I 10.

Ueber das Verhalten der normalen Adaptation. Graefe's Archiv., XXXIII, TROXLER, D. 2. I887, S. 73-112.

Ueber das Verschwinden gegebener Gegenstände innerhalb unseres Gesichtskreises. Ophthalmologische Bibliothek herausgegeben von Himly u. Schmidt, Jena, I804, I, 2, S. I-20; S. I-53.

TSCHERMAK, A.

Beobachtungen über die relative Farbenblindheit in indirectem Sehen, Ptlüger's Archiv., LXXXII, r900, S. 559-59I.

Ueber physiologische und pathologische Anpassung des Auges. Leipzig, 1900.

WALTHER, A.

Beobachtungen über den Verlauf centraler und extra-macularer negativen Nachbilder. Pflüger's Archiv., LXXVII, 1899 , S. 53-69.

WITTICH, v.

Ueber die geringsten Ausdehnungen, welche man farbigen Objecte geben kann um sie noch in ihrer specifischen Farben wahrzunehmen. Königs-

Wornow, MI. berger med. Jahrbücher, IV, 1874 , S. 22-55.

Zur Farbenempfindung. Graefe's Arcliv., XVI, I, I87o, S. 212-224.

WUNDT, W.

Beiträge zur Farbenlehre. Graefe's Archiv., XXI, 1, I875, S. 223-250.

Grundzüge der physiologischen Psychologie Leipzig, 4th edition, 1893,

Young, ThOMAS. II, S. $505 \mathrm{ff}$ : $5^{\text {th }}$ edition, 1902, II, S. $177 \mathrm{ff}$.

On the Mechanism of the Eye. Philos. Transactions, XCII, 180r, pp. $23 \mathrm{ff}$.

Miscellaneous Works. London, 1855, pp. 12ff. 


$$
\text { - }
$$





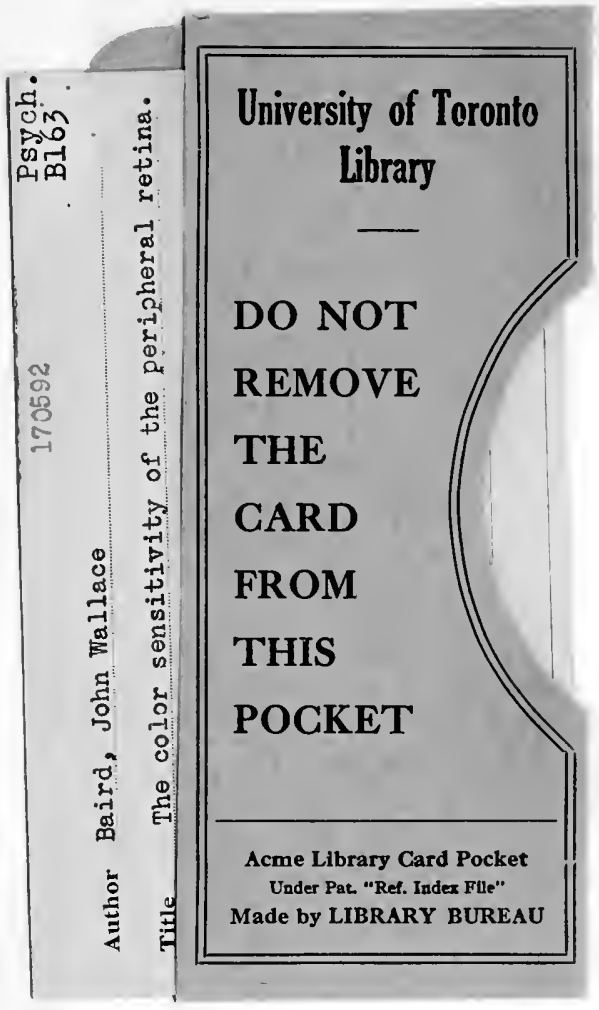


$=$
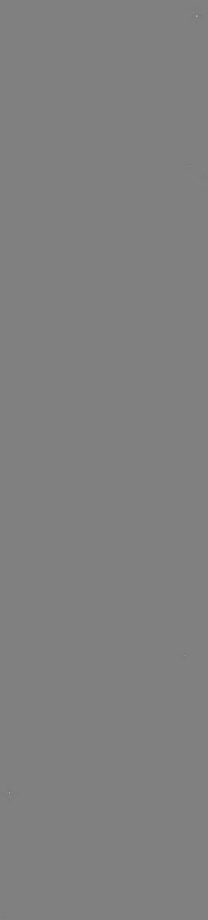

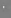

$\ldots$

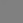

